Illinois State University

ISU ReD: Research and eData

Theses and Dissertations

3-13-2017

\title{
Proactive Personality and Voluntary Turnover: The Moderating Effects of Development and Perceived Career Opportunities
}

Amy F. Huber

Illinois State University, amyfhuber@gmail.com

Follow this and additional works at: https://ir.library.illinoisstate.edu/etd

Part of the Organizational Behavior and Theory Commons, Psychology Commons, and the Vocational Rehabilitation Counseling Commons

\section{Recommended Citation}

Huber, Amy F., "Proactive Personality and Voluntary Turnover: The Moderating Effects of Development and Perceived Career Opportunities" (2017). Theses and Dissertations. 681.

https://ir.library.illinoisstate.edu/etd/681

This Thesis is brought to you for free and open access by ISU ReD: Research and eData. It has been accepted for inclusion in Theses and Dissertations by an authorized administrator of ISU ReD: Research and eData. For more information, please contact ISUReD@ilstu.edu. 


\title{
PROACTIVE PERSONALITY AND VOLUNTARY TURNOVER: THE MODERATING EFFECTS OF DEVELOPMENT AND PERCEIVED CAREER OPPORTUNITIES
}

\author{
Amy F. Huber
}

\section{Pages}

The present thesis reports the research and quantitative examination of the relation between proactive personality and voluntary turnover, as well as the moderating influences of participation in development activities and perceptions of available career opportunities. Zeroorder correlations and moderated binary logistic regression are used to test the hypotheses within an archival data set of 295 participations from a multinational European organization. A significant correlation was found between proactive personality and participation in developmental activities. Additionally, participation in developmental activities was found to be a negative predictor of voluntary turnover. Results of the moderated logistic regression analysis showed that both participation in developmental activities and perceived career opportunities were significant moderators of the relation between proactive personality and voluntary turnover when added to the predictive models. Following an explanation of the results, the interpretation of such effects is discussed as well as the strengths, limitations, and implications for research and practice.

KEYWORDS: Proactive Personality, Voluntary Turnover, Developmental Activities, Perceived Career Opportunities 
PROACTIVE PERSONALITY AND VOLUNTARY TURNOVER: THE MODERATING EFFECTS OF DEVELOPMENT AND PERCEIVED CAREER OPPORTUNITIES

AMY F. HUBER

A Thesis Submitted in Partial Fulfillment of the Requirements for the Degree of

MASTER OF SCIENCE

Department of Psychology

ILLINOIS STATE UNIVERSITY 
(C) 2017 Amy F. Huber 
PROACTIVE PERSONALITY AND VOLUNTARY TURNOVER: THE MODERATING EFFECTS OF DEVELOPMENT AND PERCEIVED CAREER OPPORTUNITIES

\author{
AMY F. HUBER
}

COMMITTEE MEMBERS:

Alexandra Ilie, Co-Chair

Dan Ispas, Co-Chair 


\section{ACKNOWLEDGMENTS}

First and foremost, I would like to thank my co-chairs, Dr. Alexandra Ilie and Dr. Dan Ispas, as well as my reader, Dr. Margaret Nauta, for their assistance throughout the thesis process and for their valuable feedback in improving this manuscript. I would also like to thank Dr. Dragos Iliescu for providing me with the data for this study.

Thank you to all my colleagues and professors within the Industrial/OrganizationalSocial Psychology sequence, especially Dr. Eric Wesselmann and Dr. John Binning, for supporting me in my academic endeavors, making me step outside my comfort-zone, and pushing me to be my best. My gratitude also goes to Kathleen Dill for her friendship and support throughout the ups and downs of graduate school, particularly during the countless hours we spent together working on our theses.

I would like to express my appreciation to my friends (Claire, Sarah, and Marissa), my family (Erv, Nadine, Sheryl, Don, Roberta, Justin, Kyle, Ryan), and my brother, Mark, who were there to celebrate with me at every benchmark, big and little. Their frequent encouragement fueled my persistent efforts. A special thank you to Connor George for his continued reassurance throughout this trying process.

I am forever grateful for my parents, Robyn and Daniel. I cannot begin to thank you enough for your unwavering patience and selflessness. Without your guidance in my moments of discouragement and desperation, I could not possibly be where I am today.

Finally, this thesis is dedicated to my late grandmother, Lillian Huber, who supported me during my journey through graduate school in any way she possibly could.

A. F. H. 


\section{CONTENTS}

Page

ACKNOWLEDGMENTS

$\begin{array}{lll}\text { CONTENTS } & \text { ii }\end{array}$

TABLES

FIGURES

CHAPTER I: THE PROBLEM AND ITS BACKGROUND 1

Statement of the Problem 1

$\begin{array}{ll}\text { Purpose } & 4\end{array}$

CHAPTER II: REVIEW OF RELATED LITERATURE 6

$\begin{array}{ll}\text { General Literature Review } & 6\end{array}$

$\begin{array}{ll}\text { Proactive Personality } & 6\end{array}$

$\begin{array}{ll}\text { Theoretical background } & 7\end{array}$

Relationships with organizational outcomes $\quad 8$

Utility of the construct $\quad 11$

$\begin{array}{ll}\text { Voluntary Turnover } & 14\end{array}$

$\begin{array}{ll}\text { Job embeddedness theory } & 16\end{array}$

$\begin{array}{ll}\text { Proactive personality and voluntary turnover } & 17\end{array}$

Protean and Boundaryless Models of Careers $\quad 21$

$\begin{array}{ll}\text { Developmental activities } & 22\end{array}$

$\begin{array}{ll}\text { Perceived career opportunities } & 30\end{array}$

Moderators of the Relationship between Proactive Personality and Turnover 36

Developmental activities as a moderator $\quad 37$ 
CHAPTER III: RESEARCH DESIGN 46

$\begin{array}{ll}\text { Method } & 46\end{array}$

$\begin{array}{ll}\text { Participants } & 46\end{array}$

$\begin{array}{ll}\text { Measures } & 46\end{array}$

$\begin{array}{ll}\text { Proactive personality } & 46\end{array}$

$\begin{array}{ll}\text { Developmental activities } & 47\end{array}$

$\begin{array}{ll}\text { Perceived career opportunities } & 48\end{array}$

$\begin{array}{ll}\text { Voluntary turnover } & 49\end{array}$

$\begin{array}{ll}\text { Procedure } & 49\end{array}$

CHAPTER IV: ANALYSES AND RESULTS $\quad 50$

$\begin{array}{ll}\text { Summary of Analyses } & 50\end{array}$

$\begin{array}{ll}\text { Results of Correlations } & 51\end{array}$

Results of Multiple Binary Logistic Regression Analysis $\quad 52$

Participation in Developmental Activities and Voluntary Turnover 52

Perceived Career Opportunities and Voluntary Turnover 58

$\begin{array}{ll}\text { CHAPTER V: DISCUSSION } & 64\end{array}$

$\begin{array}{ll}\text { Summary of Findings } & 64\end{array}$

$\begin{array}{ll}\text { General Discussion } & 65\end{array}$

$\begin{array}{ll}\text { Limitations and Strengths } & 67\end{array}$

$\begin{array}{ll}\text { Implications for Research and Practice } & 69\end{array}$

$\begin{array}{ll}\text { REFERENCES } & 74\end{array}$ 


\section{TABLES}

Table

Page

1. Correlations and Descriptive Statistics $(\mathrm{N}=295)$

2. Deviance Statistics for Moderated Logistic Regression Analysis Results of Proactive Personality and Participation in Developmental Activities Predicting Voluntary Turnover

3. Moderated Logistic Regression Analysis Predicting Voluntary Turnover with Proactive Personality and Participation in Developmental Activities

4. Proactive Personality-Voluntary Turnover Relationship at Different Levels of Participation in Developmental Activities

5. Deviance Statistics for Moderated Logistic Regression Analysis Results of Proactive Personality and Perceived Career Opportunities Predicting Voluntary Turnover

6. Moderated Logistic Regression Analysis Predicting Voluntary Turnover with Proactive Personality and Perceived Career Opportunities

7. Proactive Personality-Voluntary Turnover Relationship at Different Levels of Perceived Career Opportunities

8. Summary of Support for Proposed Research Questions and Hypotheses 


\section{FIGURES}

Figure

Page

1. Model of Proposed Moderators of the Relation Between Proactive Personality and Voluntary Turnover

2. Plot of Two-way Logistic Regression Interaction between Proactive Personality and Participation in Developmental Activities

3. Plot of Two-way Logistic Regression Interaction between Proactive Personality and Perceived Career Opportunities 


\section{CHAPTER I: THE PROBLEM AND ITS BACKGROUND}

\section{Statement of the Problem}

Rapid technological advances, globalized competition, and organizational decentralization within the last three decades have led to the dissolution of traditional employment relationships, characterized by secure and hierarchical trajectories, in favor of selfmanaged, non-linear protean (Hall, 1987) and boundaryless (Arthur, 1994) careers (Briscoe, Hall, \& Frautschy Demuth, 2006; Garofano \& Salas, 2005; Spitzmuller, Sin, Howe, \& Fatimah, 2015). The movement towards organic career frontiers have implications for both individuals and organizations. This changing organizational landscape has shifted the responsibility of learning, development, and career management onto employees rather than their employers. As such, workers who engage in self-starting behaviors, exhibit a willingness to change, and embrace the transience and uncertainty of contemporary careers are more likely to achieve career success (Fuller \& Marler, 2009).

Research has shown that proactivity is positively related to career success (Seibert, Crant, \& Kraimer, 1999). While employees may occasionally engage in proactive behaviors, proactive personality describes the predisposition to do so; it encompasses the stable dispositional tendency to take control of one's environment and incite constructive change (Bateman \& Crant, 1993). Within organizations, proactive individuals actively customize their work environments in a way that "accentuates individual strengths and optimizes performance" (Thomas, Whitman, \& Viswesvaran, 2010, p. 278) which can include seeking information, gathering resources, role restructuring, negotiating, taking charge, and building networks. Employing proactive individuals yields a competitive organizational advantage as proactive personality is positively related to job performance (Bakker, Tims, \& Derks, 2012; Chan, 2006; Crant, 1995; Fuller \& 
Marler, 2009; Fuller Jr., Kester, \& Cox, 2010; Spitzmuller et al., 2015; Thomas et al., 2010; Thompson, 2005; Tornau \& Frese, 2013).

Having a proactive workforce has now become a necessity rather than a choice (Bergeron, Schroeder, \& Martinez, 2014). Thus, organizations must focus on the retention of such employees. Organizations already incur substantial financial losses due to voluntary turnover (Greer, 2014; Tziner \& Birati, 1996), but the voluntary turnover of proactive employees may be even more costly because these individuals are top performers (Fuller \& Marler, 2009) who anticipate potential problems (Thomas et al., 2010), and "generate and acquire value for their organizations" (Maurer \& Chapman, 2013, p. 453). Traditional research on voluntary turnover emphasizes factors that lead to employee's decisions to leave their organizations; however, job embeddedness theory (Mitchell, Holtom, Lee, Sablynski, \& Erez, 2001) attempts to explain what makes employees stay within their organizations. By examining how proactive employees function within this framework, organizations can better understand the factors that encourage proactive individuals to stay rather than leave their organizations.

It is unclear exactly how proactive personality is related to turnover because the findings of the few studies that have examined this direct relation do not converge (Allen, Weeks, \& Moffitt, 2005; Vandenberghe \& Ok, 2011). Extending the analysis to turnover intentions rather than voluntary turnover still yields inconsistent results as some studies have identified positive (Vandenberghe \& Ok, 2011), negative (Chung-Yan \& Butler, 2011; Wang, Zhan, McCune, \& Truxillo, 2011; Yang, Gong, \& Huo, 2011), and non-significant (Allen et al., 2005; Joo, Hahn, \& Peterson, 2015; Trifiletti, Capozza, Pasin, \& Falvo, 2009; Wang, Hu, Hurst, \& Yang, 2014) relations between proactive personality and turnover intentions. However, due to the tendency of proactive individuals to create a person-organization fit (Erdogan \& Bauer, 2005) via their 
active influence on their surrounding environment (Bandura, 1999), it is probable that contextual considerations which provide information about the "situated person" (Mischel \& Shoda, 2010) will provide insight into this otherwise variable relationship. No research within the extant literature that I am aware of has previously examined moderators of the relation between proactive personality and voluntary turnover.

Seibert et al. (2001) advanced that individuals with a proactive disposition "select, create, and influence work situations that increase the likelihood of career success" (p. 847). The career-focused orientation of these individuals is validated by findings which indicate proactive personality is positively related to career initiative (Fuller \& Marler, 2009; Seibert et al., 2001), planning (Presbitero, 2015), commitment (Vandenberghe \& Ok, 2011), management (Barnett \& Bradley, 2007), exploration (Cai et al., 2015), and both objective and perceived career success (Fuller \& Marler, 2009; Seibert, Crant, \& Kraimer, 1999). London's (1983) career motivation theory purports that individuals' work decisions and behaviors are fueled by their determination to achieve their desired career goals. Further, career-committed individuals are committed to specific careers rather than specific organizations (Bedeian, Kemery, \& Pizzolatto, 1991). Thus, decisions of proactive employees to stay in an organization are likely contingent on their perceptions of intra-organizational career opportunities compatible with their career goals.

Perceived career opportunities (PCO) describe employees' perceptions of the congruency between their career goals with career opportunities afforded by their organization (Kraimer, Seibert, Wayne, Liden, \& Bravo, 2011). PCO may affect proactive employees' assessments of their work environments which may in turn influence the relation between proactive personality and voluntary turnover decisions. In other words, a proactive individual's perception that they will or will not be able to achieve their career goals within their current organization should 
command whether they decide to stay with their organization or voluntarily turnover in search of other career opportunities.

An additional consideration that may shed light on the likelihood of proactive employees voluntarily leaving their jobs is their willing participation in developmental activities such as continuing education, feedback seeking, and networking (Hurtz \& Williams, 2009). Proactive individuals are likely to hold protean and boundaryless mindsets (Briscoe et al., 2006; Uy, Chan, Sam, Ho, \& Chernyshenko, 2015), which, again, are characterized by an emphasis on selfmanagement and mobility. Thus, proactive employees' participation in developmental activities may be a self-management strategy, signaling an attempt to cultivate marketable skills and enhance their employability. While ongoing skill development may be perceived favorably by organizations due to consequent enhancements in human capital (Ployhart \& Moliterno, 2011), organizations must consider if this self-sought development contributes to proactive employees' likelihood of leaving their organizations.

\section{Purpose}

Proactive employees are propitious additions to an organization's workforce because of their foresight in anticipating problems and preemptively addressing such concerns (Bateman \& Crant, 1999), as well as their commitment to improving themselves and their work environments. However, due to their tendency to change their environments to increase their likelihood of success (Seibert et al., 1999), as well as their protean and boundaryless mindsets (Briscoe et al., 2006), proactive individuals may be more committed to their careers than to their organizations (Bedeian et al., 1991). As such, understanding what leads proactive employees to voluntarily turnover and what encourages them to stay would help organizations focus on retaining these productive employees. However, the relation between proactive personality and voluntary 
turnover is not well-understood and has received very limited attention from researchers.

Therefore, the proposed study will provide further insight into this relationship. Specifically, it will investigate contextual considerations, namely participation in developmental activities and perceptions of career opportunities (Kraimer et al., 2011), that may regulate proactive employees' decisions to voluntarily turnover (Figure 1). To my knowledge, previous research has not studied moderators of this relation; thus, the present study seeks to lay the foundation for further investigation of the factors that influence or deter voluntary turnover decisions of individuals with proactive personalities.

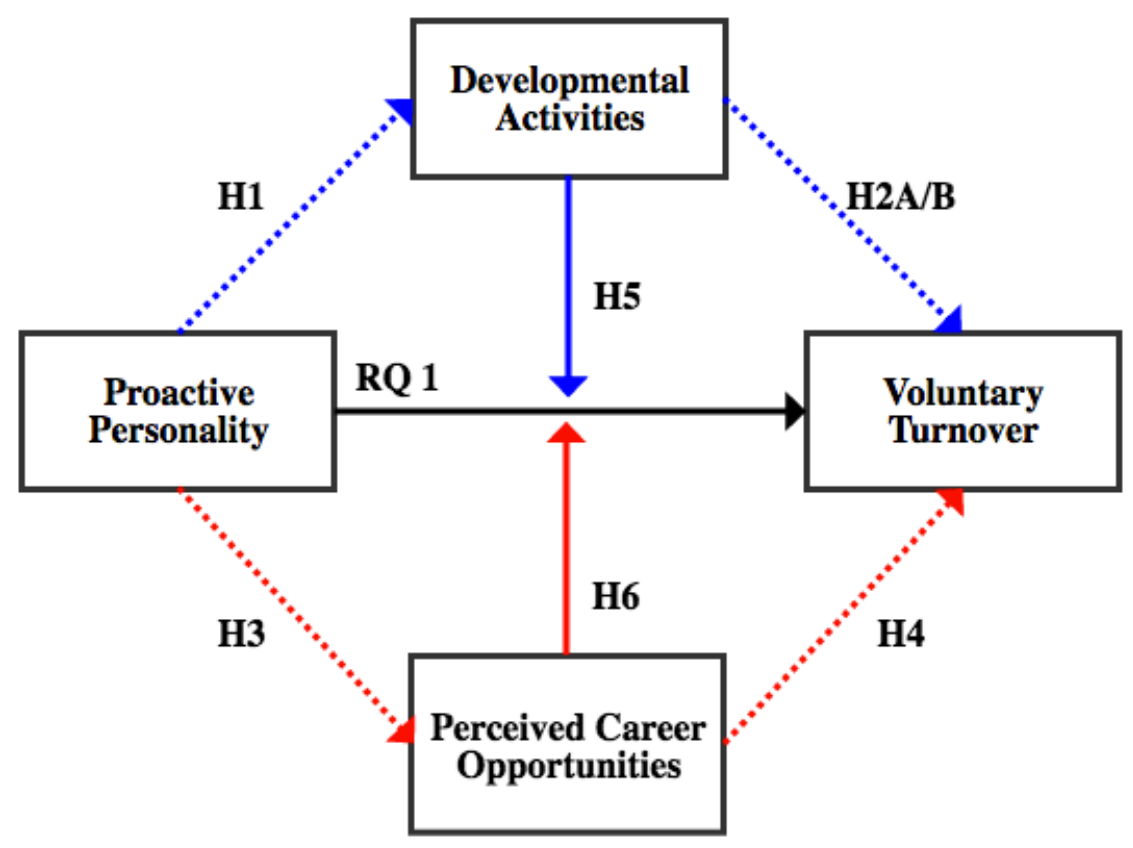

Figure 1. Model of proposed moderators of the relation between proactive personality and voluntary turnover. The relations corresponding to research questions (RQ) and hypotheses (H) within the proposed study are identified in this visual depiction. Solid lines represent the moderation hypotheses that are of focal interest to the current study. 


\section{CHAPTER II: REVIEW OF RELATED LITERATURE}

\section{General Literature Review}

\section{Proactive Personality}

In 1993, Bateman and Crant offered the primary theoretical development of the proactive personality construct to explain dispositional differences in individuals' relatively stable tendencies to influence their environments by taking action and effecting change. Individuals with proactive personalities have an innate propensity to generate and transform circumstances as active agents of their environment, which contrasts with individuals who are complacent and react to their circumstances. Proactive individuals set change-oriented goals with intentions of bettering themselves, their environments, and their organizations. Thus, they enjoy facing challenges and view them as opportunities (Bateman \& Crant, 1993; Crant, 2000). A common definition adopted within the literature states that individuals with such a disposition are "unconstrained by situational forces" and "take action and persevere until they reach closure by bringing about change" (Bateman \& Crant, 1993, p. 105). In this regard, proactive personality describes the tendency to find a person-environment fit, or rather, to beget change to create such fit (Bakker, Schaufeli, Leiter, \& Taris, 2008; Li, Zhong, Chen, Xie, \& Mao, 2014). Individuals without proactive dispositions exhibit opposing patterns of behavior, preferring to adapt to their environment rather than identifying and seizing opportunities to change their circumstances (Crant, 2000).

In organizational settings, proactive individuals are highly involved and committed to their work and may be described as "independent contributor[s] with initiative and a welldeveloped sense of responsibility," (Campbell, 2000, p. 52) as they seek information and opportunities rather than waiting for those opportunities to find them (Crant, 2000). 
Characteristic behaviors include changing work procedures and assignments; exerting influence on compensation, promotions, or distribution of rewards; anticipating and preventing problems (Bateman \& Crant, 1999); seeking out sponsorship and career support; persisting in the face of obstacles; influencing organizational strategy (Bindl \& Parker, 2011); and pursuing developmental opportunities for self-improvement, such as acquiring further skills or education (Seibert et al., 1999). Additionally, proactive employees participate in career management activities by seeking and acting upon opportunities to move to other desirable departments of an organization (Crant, 2000). In sum, these behaviors share an overall action-orientation towards work, which entails creating favorable conditions and initiating situations to achieve the forwardfocused visions and goals of the proactive individual.

Theoretical background. The foundation of the proactive personality construct is rooted in the interactionist perspective and complemented by social-cognitive theory (Bandura, 1977; Schneider, 1983). The interactionist perspective suggests behavior is controlled internally and externally and, moreover, that "situations are as much a function of the person as the person's behavior is a function of the situation" (Bowers, 1973, p. 327). That is, not only does one's surroundings affect their cognition and behavior, but one's cognition and behavior can impact their surrounding environment. Originally, the situationist school of thought minimized the role of individual differences in explaining behavior, but it became increasingly clear through social learning that intraorganismic variables could affect the behavior-environment relationship (Bandura, 1999). In essence, one's disposition and patterns of cognition prescribe their behavioral tendencies which actively influence aspects of the environment. This shifting perspective of the interactive influence of person and environment exemplifies the unification of two theoretical perspectives, namely situationism and trait theory, to form the interactionist 
perspective. Specifically, Bowers (1973) criticized discrepancies in the predictive abilities of situations and individual differences independently by suggesting that the situation is ultimately a function of the preceptor's cognitive processes, inhibiting the ability to distinguish the situation from the person or person from the situation. His introduction of the interactionist perspective and the inseparability of situation from person suggest that individuals place themselves within environments that are compatible with their behavioral tendencies (Schneider, 1983). This reciprocal relationship is paramount in the conceptualization of the proactive personality construct, as proactivity is entrenched in individuals' needs to control their environments (Bateman \& Crant, 1993).

According to social cognitive theory, a triadic reciprocal relationship exists between the person, environment, and behavior such that they continuously influence one another (Bandura, 1989). Bandura (1986) has even suggested that individuals can be proactive by stating "people create environments and set them in motion as well as rebut them" (p. 22). The proactive personality construct portrays this triadic relationship between person, behavior, and the environment by describing the personal predisposition to engage in proactive behaviors that actively influence one's environment to create a fit between their selves and their surroundings. In sum, the interactionist perspective and model of triadic reciprocal determinism (Bandura, 1989; Bowers, 1973) outline how proactive individuals actively influence their environments.

Relationships with organizational outcomes. Bateman and Crant (1993) developed the self-reported Proactive Personality Scale (PPS) to assess an individual's dispositional tendency to behave proactively. The original 17-item PPS and Seibert et al.'s (1999) abbreviated 10-item version have been used as the primary measures of proactive personality in the organizational literature. Since its development, the PPS has been utilized across a number of studies to assess 
relations between proactive personality and various organizational outcomes. Four metaanalyses have included proactive personality as a focal construct (Fuller \& Marler, 2009; Spitzmuller et al., 2015; Thomas et al., 2010; Tornau \& Frese, 2013). Taken together, their results provide a comprehensive overview of the outcomes and correlates of proactive personality. Each meta-analysis identified positive relations between proactive personality and overall job performance, ranging from $\rho=.24$ to .38. Fuller and Marler (2009) and Spitzmuller et al. (2015) also identified positive relations with task performance.

Not only are proactive employees top performers of their organizations, but they are also good citizens of their organizations. In the first meta-analysis of the proactive personality literature, Fuller and Marler (2009) showed that it was moderately and positively correlated with contextual performance $(\rho=.41)$. More recent studies not included in this initial meta-analysis have shown that, in the absence of rewards or personal benefits, proactive employees engage in organizational citizenship behaviors (OCB) (Bergeron et al., 2014; Greguras \& Diefendorff, 2010; Trifiletti et al., 2009; Yang et al., 2011) that are essential to the smooth functioning of any organization. The four meta-analyses also found proactive personality to be positively related to behaviors such as taking charge, creativity, voice, networking (Fuller \& Marler, 2009; Thomas et al., 2010; Tornau \& Frese, 2013), feedback seeking, socialization, learning, and readiness to change (Spitzmuller et al., 2015). Together, these findings provide compelling evidence for the beneficial impact proactive employees have within their organizations.

In addition to supporting organizational functioning, individuals high in proactive personality also support their own careers. The same meta-analyses have found proactive personality to be positively related to career-focused outcomes such as career initiative, career self-efficacy, job search self-efficacy, salary, promotions, career satisfaction, and both objective 
and perceived career success (Fuller \& Marler, 2009; Spitzmuller et al., 2015). Other individual studies have identified positive relations between proactive personality and career commitment (Vandenberghe \& Ok, 2011), career planning (Presbitero, 2015), and career exploration (Cai et al., 2015) as well.

Proactive employees show their support for their organizations through both their behaviors and attitudes. For instance, all four meta-analyses show that proactive personality is positively related to work attitudes such as job satisfaction and organizational commitment (Fuller \& Marler, 2009; Spitzmuller et al., 2015; Thomas et al., 2010; Tornau \& Frese, 2013). Other studies have found proactive personality to be positively related to engagement (Bakker et al., 2012), motivation to learn (Major, Turner, \& Fletcher, 2006), and self-efficacy (Li, Wang, Gao, \& You, 2017), to name a few. Spitzmuller et al.'s (2015) meta-analysis provided the only analysis of the relation between proactivity and turnover intentions, finding a very small negative correlation. However, this analysis considered just two studies, one of which measured proactive behaviors rather than proactive personality. Additionally, none of the meta-analyses report a relationship between proactive personality and voluntary turnover.

Together, the above findings suggest that, compared to their reactive counterparts, employees with proactive personalities have higher job performance, create positive work environments in their organizations, achieve more career success, and are more focused on their careers. As such, it is increasingly important for organizations to have a proactive workforce. In fact, proactivity is "becoming a necessity rather than a choice in many organizations" (Bergeron et al., 2014, p. 72). If an organization focuses on attracting, hiring, and retaining proactive employees, it will benefit from their action-oriented behaviors which drive the competitive advantage of the organization (Fuller \& Marler, 2009). 
Utility of the construct. Since the development of the PPS, research has examined the similarities between proactive personality and the Big Five personality traits (Openness, Extraversion, Conscientiousness, Agreeableness, and Neuroticism) due to the acceptance of the Big Five as a primary measure of personality across organizational research and its ability to predict a wide array of organizational behaviors. Bateman and Crant (1993) assessed the validity of the PPS by determining how proactive personality was related to the Big Five traits and found proactive personality was positively correlated with Conscientiousness and Extraversion. More recent meta-analytic research investigating the dispositional uniqueness of the construct found proactive personality was positively related to Conscientiousness, Extraversion, Openness to Experience, and Emotional Stability (Fuller \& Marler, 2009;

Spitzmuller et al., 2015; Thomas et al., 2010). Overall, these Big Five traits collectively account for $49.3 \%$ of the variance in proactive personality. Inherently, this means over $50 \%$ of the variance in proactive personality cannot be explained by the Big Five traits (Spitzmuller et al., 2015), suggesting that proactive personality may be able to explain variability in organizational outcomes beyond what is attributed to the Big Five traits. This is corroborated by research showing that proactive personality explains incremental variance in a number of outcomes beyond the Big Five personality traits.

For example, Crant (1995) found proactive personality explained $8 \%$ of the variance in job performance after controlling for known predictors like the Big Five traits, general mental ability, and work experience. More recently, the results of Spitzmuller et al.'s (2015) metaanalysis show that proactive personality explains incremental variance in overall job performance and OCB after controlling for the Big Five. In a meta-analytic examination of predictors of overall job performance, Fuller and Marler (2009) found proactive personality had 
predictive validities higher than any single Big Five factor, as well as higher predictive validity than the Big Five traits as a combined set. The ability of the dispositional construct to explain unique variance in performance and organizational behavior above and beyond the Big Five advocates for the utility of using the PPS in organizational selection contexts.

While proactive personality shares some similarity with personality constructs like positive affectivity, career optimism, and action-state orientation, there is research to suggest that proactive personality is dispositionally unique. The broaden-and-build theory of positive emotions (Fredrickson, 2001) suggests that positive affect facilitates approach behavior by momentarily broadening individuals" "thought-action repertoires" which helps to build various intellectual, social, and psychological resources. Essentially, in a positive affective state individuals begin to think about more behavioral possibilities. This increased perception of behavioral opportunities shares some degree of similarity with the tendency of proactive individuals to seek and create opportunities. Existing research has identified a modest correlation between positive affect and proactive personality (Li, Liu, Liu, \& Wang, 2016; Porath, Spreitzer, Gibson, \& Garnett, 2012). These results verify there is some degree of similarity; however, they are not large correlations, suggesting positive affect and proactive personality are two dispositionally unique constructs. They can also be differentiated from each other because proactive personality captures stable tendencies to engage in proactive behavior whereas the broaden-and-build theory of positive emotions describes momentary influences.

Likewise, there are similarities in definitions of proactive personality and career optimism, a "non-intellective motivational factor reflecting expectations of the best possible outcome in relation to one's future career development" (Tolentino, Garcia, Lu, Restubog, \& Plewa, 2014, p. 42). The similarity lies in the mutual focus on successful future career 
outcomes. However, proactive personality describes the dispositional tendency to engage in behaviors that influence one's future success, whereas career optimism describes a cognitive pattern of expectation rather than behavioral action. Researchers have identified a medium-sized correlation between career optimism and proactive personality. This verifies the two constructs share a degree of similarity but are non-collinear constructs, further advocating for the dispositional uniqueness of the proactive personality construct.

I am unaware of research that directly compares proactive personality to action-state orientation, but concerns about the conceptual overlap between the two constructs is warranted as they both share a similar emphasis on self-regulatory behavior. Action-state orientation describes an individual difference variable that influences volitional processes, or "goal-striving" (Diefendorff, Hall, Lord, \& Strean, 2000). Those who fall on the action orientation end of the spectrum are adept at devoting cognitive resources to tasks and moving quickly from one goal state to another. They are efficient and able to complete tasks even when they encounter minor setbacks. Proactive personality is similar to action orientation in the sense that environmental circumstances do not inhibit one from achieving their goals. However, I would expect proactive personality to be only modestly correlated to action orientation because proactive personality goes a step further in describing an individual's tendency to change their circumstances as opposed to acting in response to the environment. Collectively, these findings are strong indicators that proactive personality is not merely a linear combination of established traits like the Big 5, and that it is similar but conceptually unique in comparison to positive affect, career optimism, and action orientation.

Further advocating for the utility of the construct, Fuller and Marler (2009) found that proactive personality was not significantly related to social desirability, suggesting that social 
desirability is not likely to be a significant source of response bias when measuring proactive personality. Also, recent meta-analytic research found that proactive personality was not significantly related to work experience, age, or general mental ability (Spitzmuller et al., 2015; Thomas et al., 2010). These findings provide additional support for the utility of using the PPS in organizational selection contexts as a reliable measure with undistorted and unbiased responses. Thus, the measurement of proactive personality to predict individual differences in organizational behavior may become more widespread among employers seeking to identify individuals with the potential to find novel solutions and launch successful initiatives in their organizations (Bateman \& Crant, 1993). Given the positive impact proactive employees have in their organizations, the retention of such individuals should become a priority for employers. However, there is a deficiency in the proactive personality literature examining voluntary turnover decisions of proactive employees. The purpose of the proposed study is to provide insight into the influences associated with proactive individuals' decisions to stay or leave their organizations.

\section{Voluntary Turnover}

Voluntary turnover is an employee's decision to leave an organization by his or her own accord. Employee turnover can result in substantial financial losses for an organization between the costs of separation (e.g., exit interviews, severance pay, and administrative pay), replacement (e.g., advertising, interviewing, prescreening, and orientation), and new-hire training (Tziner \& Birati, 1996). By some estimates, replacement costs for a single position range from 30 to $150 \%$ of an employee's annual salary (Greer, 2014). An investment in predictive techniques aimed at identifying job applicants who are more likely to turnover can minimize the losses organizations incur from employee turnover. It is crucial to understand factors that may diminish or intensify 
rates of turnover in organizations because the "attraction and retention of high-quality employees is more important today than ever before" (Holtom, Mitchell, Lee, \& Eberly, 2008, p. 232).

Antecedents of employees' voluntary turnover decisions have been covered extensively in the extant literature. Holtom and colleagues (2008) provided a comprehensive summary, differentiating the numerous antecedents into individual differences, the nature of the job, attitudes, organizational context, and person-context interface. For instance, work attitudes such as job satisfaction, organizational commitment, perceptions of fairness, and turnover intentions are consistently found to be proximal predictors of employee turnover (Heavey, Holwerda, \& Hausknecht, 2013). Turnover intentions are often studied as a precursor of actul turnover due to difficulty in collecting retention data at a second point in time. While intentions do not perfectly predict turnover, they are not independent of each other (Bedeian et al., 1991; Parasuraman, 2010; Podsakoff, LePine, \& LePine, 2007; Steel \& Ovalle, 1984). Thus, research measuring turnover intentions can still provide critical information to better understand voluntary turnover decisions.

Existing research has repeatedly shown a number of individual difference constructs such as self-confidence, core self-evaluation (Holtom et al., 2008), Emotional Stability, Conscientiousness, Agreeableness (Barrick \& Mount, 1996; Zimmerman, 2008), positive and negative affectivity, and general mental ability (Zimmerman, Swider, Woo, \& Allen, 2016) to be related to voluntary turnover. In comparison to attitudes and situational characteristics contingent on organizational context, understanding how individual differences contribute to turnover decisions is advantageous for organizations in the selection process looking to assess such proclivities before employees are entrenched in the organizational context. 
Not all turnover is created equal; the voluntary turnover of poor performers actually benefits organizations (Holtom et al., 2008). Therefore, the importance of studying voluntary turnover lies in understanding factors that influence top-performers to stay or leave their jobs and organizations. While traditional turnover theories focus on employees' decisions to terminate employment relationships, recent research focuses on their decisions to stay with their organizations.

Job embeddedness theory. Mitchell and colleagues (2001) directly address the importance of understanding incentives to stay by introducing job embeddedness theory, which focuses on factors that influence employee's decisions not to leave their jobs (Holtom et al., 2008). Embeddedness is characterized by the extent to which (a) individuals have links to other individuals or activities, (b) their jobs are similar to and fit with other features of their life, and (c) how easily links can be broken, as well as what they would leave behind if they leave (Mitchell et al., 2001). These components are referred to as links, fit, and sacrifice, respectively.

Links are formal or informal connections between employees, institutions, or other individuals. The more links an employee has in the work environment, the more the employee is bound to their organization. The decision to leave one's organization would require the disconnection or readjustment of such links. Fit refers to an employee's perception of their compatibility or comfort within their organization (Mitchell et al., 2001). Job embeddedness theory suggests that for an employee to remain in their organization, their values, career goals and interests, and plans for the future need to "fit" within the overarching organizational culture and job demands. Sacrifice describes an individual's perceptions regarding the costs associated with the loss of material or psychological benefits (e.g., colleagues, healthcare plans, or, less visibly, job stability and opportunities for advancement) by leaving one's job; it is increasingly 
difficult for employees to leave an organization if they must make large sacrifices (Mitchell et al., 2001). Job embeddedness has been found to improve predictions of voluntary turnover beyond the effects of job satisfaction, organizational commitment, perceived alternatives, and job search (Mitchell et al., 2001). Perceptions of job embeddedness are highly subjective, and, thus, conditional on individuals' personality and experiences. As such, job embeddedness theory can provide a framework to help explain how dispositional differences are related to voluntary turnover decisions.

Proactive personality and voluntary turnover. In discussing the importance of retaining top performers, Holtom, Mitchell, and Lee (2006) note the best employees are individuals who "challenge the status quo, have a longer term focus, love learning, and possess a willingness to take risks" (p. 317). The consonance between this description and that of proactive employees is remarkable because, as previously discussed, proactive individuals are likely to challenge the status quo, set change-oriented goals, achieve results, and create rather than adapt to new circumstances (Bateman \& Crant, 1999). Considering the array of positive organizational outcomes that proactive personality is associated with, it is clear that the attraction and retention of proactive individuals should be of particular interest to organizations.

Currently, I am aware of only two studies that examine the direct relation of proactive personality to turnover. While the inclusion of turnover intentions expands this body of literature, the influence of proactive personality on employees' decisions to stay in one's organization remains relatively under-researched. There is little consensus on the significance or direction of this relationship due to inconsistent findings across studies. Some research has found proactive personality to be negatively related to turnover intentions. For instance, Wang et al. (2011) included proactive personality as a covariate in a mediation model where a number of 
fit variables mediated the relationship between adaptability and turnover intentions. Proactive personality was not tested as a predictor in the model, but the researchers did find a negative correlation between proactive personality and turnover intentions. Chung-Yan and Butler (2011) examined proactive personality as a moderator of the relationship between job complexity and turnover intentions. Proactive personality did not interact with job complexity to predict turnover intentions, but proactive personality did negatively predict turnover intentions independently. The authors did not discuss this finding as it was not a focus of their study.

Yang and colleagues (2011) also found that proactive personality was negatively related to turnover intentions, though this was an indirect relationship mediated by both information exchange and trust. The researchers drew on social-capital theory to explain that proactive individuals form interpersonal relationships through networking which embed them within their organization and reduce turnover intentions. This speaks to the link constituent of job embeddedness theory (Mitchell et al., 2001). As proactive individuals form interpersonal relationships, or links, at work through information exchange and trust building, their turnover intentions will decrease. Thus, job embeddedness theory serves as a good basis to explain one potential reason why proactive individuals may be likely to stay within their organizations.

However, not all research regarding the relation between proactive personality and turnover intentions converge to the same conclusion. Vandenberghe and Ok (2011) examined the moderating effects of proactive personality on the relations between career commitment and job embeddedness, turnover intentions, and turnover. While proactive personality did not moderate the relation between career commitment and turnover, it did moderate the relations between career commitment and both job embeddedness and turnover intentions. Specifically, career commitment was positively related to turnover intentions for those high in proactive personality, 
but negatively related to turnover intentions for those low in proactive personality. The opposite pattern was exhibited when predicting job embeddedness. The researchers explain these finding by advocating that proactive individuals actively scan their environments in search of opportunities that serve their career goals, which may ultimately involve leaving one's organization in cases of high career commitment (Vandenberghe \& Ok, 2011).

Although proactive personality did not moderate the relation between career commitment and turnover, the authors did find a positive correlation between proactive personality and turnover. This finding was not explicitly discussed, as the researchers were only interested in proactive personality as a moderator. However, job embeddedness theory might suggest that these proactive individuals did not choose to stay with their organizations because they did not perceive a fit with their environment; thus, they may have been more likely to turnover in search of a better fit outside of their organization. Therefore, Vandenberghe and Ok's (2011) findings suggest that proactive individuals who are committed to their careers will consider breaking links and making sacrifices to find an environment that is more fit to their interests.

Furthermore, a number of studies did not find significant relations between proactive personality and turnover intentions (Allen et al., 2005; Joo et al., 2015; Trifiletti et al., 2009; Wang et al., 2014) or turnover (Allen et al., 2005). Allen and colleagues (2005) examined proactive personality as a possible moderator of the turnover intention-turnover relationship. Because proactive individuals are more likely to actively pursue opportunities that align with their career interests, the authors hypothesized that turnover intentions would be a stronger predictor of turnover for individuals high in proactive personality. However, the results did not support this hypothesis (Allen et al., 2005). Further, proactive personality was not significantly correlated with turnover intentions or turnover. 
Taken together, the aforementioned findings obfuscate the true nature of the relation between proactive personality and turnover. Some studies suggest proactive personality is positively related to turnover and turnover intentions (Vandenberghe \& Ok, 2011), negatively related to turnover intentions (Chung-Yan \& Butler, 2011; Wang et al., 2011; Yang et al., 2011), or not significantly related to turnover (Allen et al., 2005) or turnover intentions (Allen et al., 2005; Joo et al., 2015; Trifiletti et al., 2009; Wang et al., 2014). As such, researchers have highlighted the need for continued investigation of this relationship.

Additionally, there is limited theoretical development offered as to why proactive personality may or may not be related to turnover. More research has examined the relation between proactive personality and turnover intentions than with actual turnover (Joo et al., 2015). This may largely be a manifestation of the difficulty involved in collecting turnover data as it requires time-lag data collection. Due to the inconsistent findings relating proactive personality to turnover intentions and the lack of literature relating proactive personality to turnover, the proposed study aims to contribute to this inconclusive literature and offer possible theoretical development by posing a research question to investigate this relationship.

Research question 1. How is proactive personality related to voluntary turnover?

The lack of consensus examining this relationship gives way to an important consideration: the relation between proactive personality and voluntary turnover may be highly dependent on contextual factors. It is likely that personal experiences or situational constraints interact with proactive personality to explain decisions to stay or leave an organization. Given the importance of managing turnover in organizations, it is not only essential to understand if employees' individual differences are related to such behaviors, but also why these differences lead to different turnover decisions (Zimmerman et al., 2016). Therefore, in addition to 
exploring the direct relation between proactive personality and turnover, the proposed study aims to provide insight into the contextual circumstances that influence proactive employees' decisions to stay in their respective organizations.

\section{Protean and Boundaryless Models of Careers}

In the past, many organizations established rigid hierarchical structures to operate successfully within stable environments. As a result, careers were secure and linear. However, the flattening of this structure in recent decades has resulted in the adoption of more contemporary configurations to address the fluidity and unpredictability within ever-changing business environments. The growing recognition of protean and boundaryless career views exemplify this shift, emphasizing blurred career boundaries, the breaking of traditional organizational norms, and an increased emphasis on personal accountability for career management (Briscoe et al., 2006). A protean career (Hall, 1987) is one that is driven by an individual, emphasizes professional growth, and changes as both the person and environment change (Fuller \& Marler, 2009). Individuals' core values, rather than the organization's, drive their careers and they are the ones who subjectively assess their own career success (Hall, 2004). A boundaryless career describes employment that moves across the boundaries of multiple employers and is "independent from traditional organizational career principles" (Arthur, 1994, p. 296). An individual with a boundaryless career mindset navigates the changing work landscape with varying levels of physical and psychological movement (Briscoe et al., 2006; Sullivan \& Arthur, 2006).

As such, employees must proactively seek opportunities for growth and development as a means of managing protean or boundaryless careers and navigating changing organizational environments. As organizations adopt contemporary structures in favor of their traditional 
predecessors, employees who proactively navigate ever-changing circumstances efficaciously are of increasing value to their employers, as evidenced by the positive relations between proactive personality and job performance (Bakker et al., 2012; Chan, 2006; Crant, 1995; Fuller \& Marler, 2009; Fuller Jr. et al., 2010; Spitzmuller et al., 2015; Thomas et al., 2010; Thompson, 2005; Tornau \& Frese, 2013). Additionally, work in contemporary organizations is comprised of many "weak" situations where employees' personalities have substantial influence on their behaviors (Mischel, 1977; Seibert et al., 1999); this is contrasted with "strong" situations where highly structured circumstances dictate acceptable and expected behavior, minimizing the influence of personality on organizational behavior. As organizations rely less on traditional employment scenarios, differences in personality should become increasingly important in how employees approach these "weaker" circumstances. Thus, personality should influence how individuals self-manage protean and boundaryless careers.

This is corroborated by findings that proactive personality is positively related to boundaryless mindset and self-directed protean attitude (Uy et al., 2015), career-management, mobility preference (Briscoe et al., 2006), career and job search self-efficacy, and learning goal orientation (Fuller \& Marler, 2009). Further, individuals high in proactive personality actively manage their careers through career planning, skill development, and engaging in career development activities (Seibert et al., 1999).

Developmental activities. The shift towards protean careers has shifted the responsibility for learning from organizations to individuals (Garofano \& Salas, 2005). Employees must ensure their skills are current and marketable by engaging in ongoing development. Developmental activities, also referred to as career enhancement opportunities, are an assortment of multi-modal activities and experiences aimed at developing employees' 
knowledge or skills that are seen as valuable towards the augmentation of one's work-related competence. This includes continuing education, employee assessment and feedback, engaging in new on-the-job experiences, and developing a network of professional relationships (Hurtz \& Williams, 2009). Continuing education includes participation in training, coursework, workshops, and seminars; assessment activities include receiving feedback from supervisors, coworkers, clients, and conducting self-assessments; on-the-job experiences include new projects and job rotations; and career enhancing opportunities associated with professional development include activities centered around networking, receiving coaching/mentoring, or consulting with experienced employees (Hurtz \& Williams, 2009).

As previously discussed, when individuals are immersed in more protean and boundaryless careers they become increasingly responsible for their own development necessitating participation in various activities to enhance their skills and learn continuously by their own accord. Therefore, it is important to understand the drivers of employees' decisions to participate in such developmental activities (Hurtz \& Williams, 2009). Because individual differences largely influence organizational behavior (Li, Barrick, Zimmerman, \& Chiaburu, 2014), it is likely that they would also affect participation in career enhancing activities.

In a study of 427 employees from four organizations, Hurtz and Williams (2009) investigated various attitudinal and motivational antecedents of employee's decisions to participate in developmental activities. The researchers identified three dispositional antecedents, namely learning goal orientation, job involvement, and work centrality, which were all positively related to employees' participation in developmental activities; this suggests that individuals who prioritize work in their lives are more likely to find utility in participating in activities focused on developing work-relevant skills and knowledge (Hurtz \& Williams, 2009). 
Of the three antecedents, learning goal orientation, or the "desire to develop the self by acquiring new skills, mastering new situations, and improving one's competence" (Vandewalle, 1997, p. 1000), had the greatest direct impact on attitudes toward participation in career enhancing opportunities. A number of studies have found learning goal orientation to be positively and strongly related to proactive personality (Maurer \& Chapman, 2013; Orvis \& Leffler, 2011; Tolentino et al., 2014) supporting the notion that proactive individuals may be more motivated to seek development opportunities to enable them for career success (Seibert et al., 1999). Tolentino et al. (2014) explain that proactive individuals are likely to prepare for career-related changes due to their tendencies to identify areas for improvement. Meta-analytic research does suggest that personality variables do have a moderate to strong relationship with motivation to learn (Colquitt, LePine, \& Noe, 2000).

Though Colquitt et al. (2000) did not include proactive personality in their analysis, recent research has examined the influence of proactive personality on motivation to participate in developmental activities. Bertolino and Fraccaroli (2011) recently identified proactive personality as a predictor of training motivation in a sample of 272 government employees. Likewise, Major et al. (2006) found that proactive personality was indirectly related to participation in developmental activities via motivation to learn. The authors stated that the proactive personality construct "fits well conceptually with the...emphasis on career selfmanagement and self-directed learning opportunities" (p. 934).

It is important to note, however, that while training motivation and participation in developmental activities in the above studies does in part reflect trends in the motivation of proactive individuals to seek learning opportunities, training was provided by the organization. This suggests the situational strength (Mischel, 1977) of training was "strong" in these instances. 
That is, because the training activities were offered by the organization, motivation to engage in such activities might not have been strongly influenced by personality. The self-development scenario is "weaker" because participation is not mandated by organizations and employees must be motivated to learn by their own discretion; as such, personality is likely to have a stronger influence on employee's participation in self-sought developmental activities. Nonetheless, Bertolino and Fraccaroli (2011) and Major et al. (2006) still found significant effects which only advocates for the likelihood of finding these same effects in weaker scenarios.

Ok and Vandenberghe (2016) recently found that proactive personality was positively correlated with participation in competence development activities. This positive association substantiates the idea that proactive employees may be more likely to seek and participate in career enhancing activities as a tactical strategy to ensure their preparedness and competence to take on future challenges and endeavors. Especially as employees become more responsible for their self-development, proactive individuals should be more likely than their reactive counterparts to take additional efforts to learn continuously given the self-starting agency inherent to their dispositions. In one study, participants indicated how often within the past year they completed 19 listed self-development activities and an overall score was created by averaging the total frequencies (Orvis \& Leffler, 2011). The authors found proactive personality was directly and positively related to the quantity of self-development participation. Therefore, based on the aforementioned findings and learning orientation of proactive individuals, the current study expects proactive personality will be positively related to participation in career enhancing opportunities and developmental activities.

Hypothesis 1. Proactive personality will be positively related to participation in developmental activities. 
Employees' voluntary participation in developmental activities and career enhancing opportunities is often viewed favorably from an organization's perspective. Human capital, or the amalgamation of employees' knowledge, skills, and abilities (Ployhart \& Moliterno, 2011), is an organization's most essential asset for success. Therefore, employees' self-guided development would be viewed approvingly by organizations because their augmented job-related skills and abilities can be leveraged to enhance performance and gain a competitive advantage. Therefore, organizations that strive to retain employees who develop highly desired skills through participation in such activities will benefit from their continued growth.

From the employee's perspective, however, the matter is more convoluted. On one hand, engaging in developmental activities should encourage employees to stay in their organizations because improvements in general skills and knowledge should better prepare employees for internal advancement (Bambacas \& Kulik, 2012). On the other hand, employees' participation in career enhancing activities might encourage voluntary turnover. As employees engage in developmental activities and cultivate marketable skills, they become more employable from the eyes of other organizations; so, employees may leave their current organizations for another. These two conflicting views are substantiated by mixed findings within the extant literature on the relation between employees' participation in developmental activities and voluntary turnover.

In line with social exchange theory (Blau, 1964), which offers that employees stay within their organizations to reciprocate benefits they have received from their organization (Eisenberger, Armeli, Rexwinkel, Lynch, \& Rhoades, 2001), some researchers have found that growth opportunities were indirectly and negatively related to turnover and turnover intentions (Allen, Shore, \& Griffeth, 2003). Growth opportunities in this study were defined as opportunities to improve skills and knowledge and are conceptually parallel to the present 
definition of developmental activities. However, Allen et al. (2003) focused on perceptions of organizational support and the availability of opportunities, stating that the perceived support employees experience when they participate in developmental opportunities provided by their organizations creates feelings of obligation. The norm of reciprocity (Gouldner, 1960) suggests that individuals feel obligated to help those who have helped them; so, employees who feel that the organization has provided them with the opportunity to participate in developmental activities will attempt to repay the organization by staying with the organization (Allen et al., 2003). Similarly, Wayne, Shore, and Liden (1997) found developmental experiences were negatively correlated with intentions to quit. Their model also focused on perceived support as a key mediator, and thus, they also emphasized that an employee who participated in developmental experiences provided by an organization would be less likely to turnover because of the social-exchange relationship.

While the availability of developmental activities and organizational support for development are distinct from participation in such activities, their relationships with turnover and turnover intentions may be quite similar. Blau (1964) specified that employees may take long-term approaches to social-exchange relationships with their organizations, where the balance in exchanges and reciprocity unfolds over time (Wayne et al., 1997). Considering that developmental activities can take a number of forms (e.g., continued education, employee assessment, networking, etc.), the reciprocated act of staying with an organization after developing marketable skills might not reciprocate the availability of the developmental opportunity itself, but rather an exchange that was inherent to the specific activity.

For instance, consider an employee establishing a mentor relationship with a senior member of the organization and that it was not formally ascribed by the organization, but rather 
sought on the employee's free will. The mentee may feel the need to reciprocate (Gouldner, 1960) the mentor's efforts that were extended to his or her development by applying their newfound skills intra-organizationally. Here, the mentee is not reciprocating the availability of an opportunity offered by the organization, but rather balancing the exchange between their self and the mentor. This example depicts the manifestation of a social-exchange relationship unfolding over time, and not explicitly involving perceptions of organizational support. This illustration also shows how such an exchange may create links with another employee, thereby embedding the mentee in the organization and deterring them from voluntarily turning-over.

Still, there is evidence to suggest that participation in developmental activities increases the likelihood that an employee will turnover. For example, Benson, Finegold, and Mohrman (2004) found that employees who took classes through a tuition reimbursement program in their organization were less likely to quit in comparison to employees who did not participate in the program; however, when these employees completed their courses and earned their graduate degrees, their likelihood of turnover increased by over 75 percent compared to those still taking classes. These findings suggest that an employee's desire to complete their degree may induce temporary staying incentives in order to continue receiving tuition reimbursement benefits, but this incentive to stay is ultimately replaced by intentions to leave once the benefit of participation in the developmental activity and growth in their human capital is fully realized.

Relatedly, Ito and Brotheridge (2005) tested a model to see if supporting employees' career adaptability would lead to commitment, turnover, or both. In this study, career adaptability was measured as a latent variable with career resilience and career development activities as its indicators. The researchers found career adaptability was somewhat of a doubleedged sword; although increased career adaptability enhanced affective commitment, it also 
strongly increased employee's turnover intentions both directly and indirectly via dependence. Ito and Brotheridge (2005) proposed that because organizations place the responsibility for selfdevelopment on employees, these individuals increase their career adaptability without forming any sort of commitment to the organization. In this sense, because the developmental opportunities do not occur within the organization, there is no social-exchange that employees feel the need to reciprocate. From a human capital perspective, while employee development increases their productivity in their organizations, it also augments their employability in the market which may increase the rate of turnover to pursue other jobs (Rahman \& Nas, 2013).

The theoretical development in the extant literature related to participation in developmental activities is limited, as there are relatively few studies directly examining the relationship between participation in developmental activities and turnover that do not focus on felt obligation to reciprocate the organizational provision of development opportunities. However, the conceptual parallels between many of the aforementioned variables provide valuable insight into the possible nature of the relation between participation in career enhancing opportunities and voluntary turnover. While most of these studies investigated relations with turnover intentions as opposed to actual turnover, clearly there is disagreement regarding the effect of participation in career enhancing activities on employees' intentions to stay within their organization, which necessitates further examination of this relationship.

Therefore, the proposed study will investigate the relation between participation in developmental activities and voluntary turnover. There is evidence to suggest that participation in developmental activities may serve to embed an employee with their organization by creating links (Allen et al., 2003; Wayne et al., 1997) and creating a sense of obligation to reciprocate social-exchanges (Blau, 1964; Gouldner, 1960; Wayne et al., 1997). However, there is also 
evidence to suggest that participation in developmental activities enhances one's career adaptability (Rahman \& Nas, 2013), and their ability to move inter-organizationally and voluntarily leave their organizations (Benson et al., 2004; Ito \& Brotheridge, 2005). Therefore, the proposed study offers two competing hypotheses to examine how these variables are related to each other.

Hypothesis 2a. Participation in developmental activities will negatively predict voluntary turnover.

Hypothesis $2 \boldsymbol{b}$. Participation in developmental activities will positively predict voluntary turnover.

Perceived career opportunities. Kraimer and colleagues (2011) introduced the perceived career opportunities (PCO) construct to better understand the contingencies of the relation between organizational support for development and various organizational outcomes. They also developed a measure to quantify perceptions of career opportunities. PCO is defined as “employees' perceptions of the degree to which work assignments and job opportunities that match their career interests and goals are available within their current organization," (Kraimer et al., 2011, p. 488). Said differently, PCO captures the extent to which employees believe that employment within their current organization is conducive to the achievement of their workrelated aspirations. It is imperative to note that, by nature, $\mathrm{PCO}$ are acuities that are conditional on subjective interpretation due to idiosyncratic variability in career goals and interests, exposure to different career options within an organization, specific employment history, and/or personal life experiences. For instance, an employee's perception of the possibility of upward promotion represents one specific perceived career opportunity if the employee desires the prospect of hierarchical mobility. However, it is not necessary for PCO to involve such vertical movement 
through an organization if that movement does not align with the employee's interests. This highlights the dependence of PCO on subjective variation in ideal career trajectories (Kraimer et al., 2011).

Even if two employees work within the same organization, their interests in specific opportunities may be vastly different. Some examples include seeking specific opportunities to work in different countries, to participate in start-up efforts, to work within flexible arrangements to accommodate work-family considerations, or to work on a specific project to develop a particular skill set. As employees gain work experience, set various career goals, and engage in career planning activities, their awareness of and perceptions of career opportunities within their organizations may change (Kraimer et al., 2011). This large variability attests to the contextual and intra-individual dependency of perceived career opportunities, suggesting that PCO are not fixed but rather reflective of circumstantial perceptions of fit between an employee's career goals and perceived opportunities to work towards such goals within their current organizations.

As previously discussed, in the era of protean/boundaryless careers and increased fluidity of "new employment relationships" (Arthur, 1998), employees are increasingly responsible for managing their own careers. Therefore, Kraimer et al. (2011) identified the PCO construct as a critical contextual consideration in employees' assessments of their work environments. The logic underlying the importance of PCO in explaining employees' organizational behavior is largely derived from London's (1983) Career Motivation Theory. This theory describes career motivation as a multidimensional concept delineated into three domains: career resilience, career insight, and career identity. Resilience describes the ability to adapt to changing circumstances; insight consists of establishing specific career goals; and identify reflects the degree to which one defines their self by their work (London \& Noe, 1997). The latter 
constituent is considered the directional component of career motivation (Noe, Noe, \& Bachhuber, 1990), reflecting an individual's inclination to pursue advancement opportunities or make sacrifices in order to achieve career objectives. Noe et al. (1990) found that the selfreported congruence of individual and organizational career plans was positively related to an individual's career identity. While Noe et al.'s (1990) research preceded that of Kraimer et al. (2011), the notion of individual and organizational career plan congruence is conceptually parallel to the central tenet of the PCO construct. In essence, career motivation theory suggests that employees' work behaviors and decisions are motivated by one's desire and determination to achieve their respective career goals (Kraimer et al., 2011).

Due to the dependency on individual perceptions, it is probable that perceptions of career opportunities are related to specific individual difference variables and their concurring differential patterns of cognition. However, no prior research that I am aware of has tested any such hypotheses. Given the foundation of PCO upon career motivation theory (London, 1983), it is likely that individual differences in career-oriented motivation are related to PCO. In considering the components of career motivation theory, one may identify similarities of career resilience, insight, and identity with the proactive personality construct. Empirical research has identified positive relations between proactive personality and myriad career-oriented behaviors such as initiative (Fuller \& Marler, 2009; Seibert et al., 2001), planning (Presbitero, 2015), exploration (Cai et al., 2015), commitment (Vandenberghe \& Ok, 2011), satisfaction (Converse, Pathak, DePaul-Haddock, Gotlib, \& Merbedone, 2012; Erdogan \& Bauer, 2005; Seibert et al., 1999), career management (Barnett \& Bradley, 2007), and objective and perceived career success (Fuller \& Marler, 2009; Seibert et al., 1999). 
It is evident that proactive individuals have career insight and identity by setting specific career goals they want to achieve and taking it upon themselves to do what it takes to reach them. Additionally, individuals high in proactive personality are likely to "select, create, and influence work situations that increase the likelihood of career success" (Seibert et al., 2001, p. 847). This builds upon the career resiliency component of career motivation theory, because not only do proactive individuals adapt to changing circumstances, but they create changing circumstances. This awareness of and impact on one's environment suggests that proactive individuals may be particularly cognizant of contextual factors in their environments: specifically, potential opportunities that are related to their career goals and interests. In fact, Erdogan and Bauer (2005) identified a positive relation between proactive personality and perceived person-organization fit in two separate studies. While personorganization fit is distinct from perceived career opportunities, there is, to some extent, conceptual overlap between the two constructs. PCO is essentially a measure of perceived fit between an individual's career goals and the ability to satisfy those goals within one's organization while perceived person-organization fit measures perceptions of congruence between individual and organizational values and goals. Considering the limited literature on PCO, understanding the subjective perceptions of fit between individuals and their organizations provides some insight into the probable nature of the relation between proactive personality and PCO. Proactive employees customize their environments to accentuate their strengths and optimize performance (Thomas et al., 2010), and this customization includes seeking or creating career opportunities that coincide with individual goals.

In examining the influence of proactive personality on career-focused mentoring behaviors and perceptions of career plateaus in a banking organization, Wang et al. (2014) found 
proactive personality was negatively related to perceptions of job content plateaus. Such perceptions capture the belief that one's job lacks challenges or responsibility, as well as their perception of the over-all "staleness" of the job. The authors suggested that those high in proactive personality may have "perceived the option of additional strategies for improving their career situations" (p. 326). Conversely, those low in proactive personality might be less likely to perceive a variety of opportunities for managing their careers. This explanation is concordant with the present theorization that proactive individuals are more attuned to information and opportunities in the environment that are congruent with one's interests and career-goals; thus, they would be more likely to perceive career opportunities. Therefore, the proposed study will contribute to the paucity of literature surrounding the PCO construct by considering dispositional differences in the tendency to perceive career opportunities within one's environment. Because proactive individuals identify, seek, and generate opportunities that are congruent with their career goals and interests (Seibert et al., 1999) and are highly motivated to manage their careers, the proposed study expects that proactive personality will be positively related to PCO.

\section{Hypothesis 3. Proactive personality will be positively related to perceived career}

\section{opportunities.}

Aside from introducing the PCO construct, Kraimer et al. (2011) examined the influence that perceived career opportunities had on organizational behavior such as job performance and turnover in a sample of employees from a Fortune 500 manufacturing company in the United States. After controlling for education, job satisfaction, organizational commitment, organizational support for development, and perceived job alternatives, the authors found PCO was a significant, negative predictor of voluntary turnover. That is, when employees perceived more career opportunities in their organization they were less likely to turnover. Chay and Aryee 
(1999) also found a negative relationship between perceived career growth opportunities and turnover intentions. While turnover intentions and actual turnover are not commensurate, again, they are not independent of each other (Bedeian et al., 1991; Podsakoff et al., 2007; Steel \& Ovalle, 1984). Therefore, the negative relation between perceived career growth opportunities and turnover intentions (Chay \& Aryee, 1999) suggests that a lack of perceived career opportunities may also be related to employees' voluntary departure decisions. In other words, if employees believe that their organization lacks career opportunities aligned with their career goals, they may be likely to leave the organization in search of opportunities to satisfy their career goals and interests elsewhere. Likewise, Allen et al. (2003) found employee's perceptions of the availability of growth opportunities were negatively correlated with voluntary turnover. Although growth opportunities do not fully capture the PCO construct, there is conceptual similarity in that both constructs capture employee's perceptions of the provision of opportunities that may be instrumental to achieving an employee's job-related goals. As employees take on more responsibility for self-managing their own protean careers (Arthur, 1994), they will assess the fit between the perceived availability of career growth opportunities and their desired career goals. Therefore, if perceived career opportunities are low, employees may be more likely to voluntarily turnover as a means of self-managing their careers.

The career identity component of career motivation theory (London, 1983) reflects an individual's inclination to pursue opportunities or make sacrifices to achieve their career objectives. As such, the relevance of career motivation theory to the relation between PCO and voluntary turnover is two-fold. First, this theory would suggest that if an opportunity existed outside of one's organization that would satisfy that employee's career goals, they would be likely to leave their current organization in pursuit of the more compatible opportunity. Second, 
inherent in the definition of career identity is the notion of making sacrifices in order to achieve one's career goals. This is directly related to the sacrifice dimension of job embeddedness theory (Mitchell et al., 2001), which reasons that if employees believe they must make considerable physical or psychological sacrifices when leaving an organization, they will be less likely to voluntarily turnover. So, these two theories suggest that if an individual is highly committed to their career they will be willing to make sacrifices to achieve their career goals, thus reducing their embeddedness and making voluntary turnover easier for that employee.

While Kraimer et al.'s (2011) research highlights the utility of the PCO construct in understanding the influence of individuals' career considerations on their organizational behavior (London, 1993), the PCO construct has not been studied further since its introduction. The embodiment of the protean career, motivation to pursue career goals, and lack of embeddedness all suggest that PCO would be negatively related to voluntary turnover. This is ratified by Kraimer et al.'s (2011) and Chay and Aryee's (1999) findings that perceived career opportunities were negatively related to turnover and turnover intentions, respectively. Therefore, the current study expects that PCO will be negatively related to turnover.

Hypothesis 4. Perceived career opportunities will negatively predict voluntary turnover.

\section{Moderators of the Relationship between Proactive Personality and Turnover}

The inconclusive results concerning the relationship between proactive personality and turnover may indicate the presence of moderating variables. Two such factors may be participation in developmental activities and perceptions of career opportunities within an organization. These contextual considerations may be seen as "pushing or pulling" factors, that when experienced by proactive individuals, may make them more likely to actively pursue alternatives that involve quitting (Allen et al., 2005). To my knowledge, moderators of the 
relationship between proactive personality and voluntary turnover have not previously been researched. Thus, the proposed study aims to provide the first consideration of such moderating effects by investigating the influence of development and perceived career opportunities on the relation between proactive personality and voluntary turnover.

Developmental activities as a moderator. Previous research showing a positive relation between proactive personality and participation in developmental activities suggests that proactive individuals are more likely to participate in career enhancing activities as a means of preparing for future endeavors (Ok \& Vandenberghe, 2016; Orvis \& Leffler, 2011) and to help them advance their career goals and interests (Allen et al., 2005). Additionally, prior studies showing that proactive individuals are more committed to their careers (Vandenberghe \& Ok, 2011) and engage in more proactive career planning (Presbitero, 2015) than non-proactive individuals suggest that employees with this disposition take it upon themselves to proactively manage their career trajectories. Proactive employees' participation in developmental activities provides a signal about preparations for future rather than current circumstances because employees with proactive personalities are forward thinkers and take steps to plan for the future (Bateman \& Crant, 1993).

A reactive employee participates in developmental activities to enhance their ability to carry out a given task within their organizations as a reactive response to the demands of a current situation. Conversely, a proactive employee who participates in developmental activities to enhance their ability to perform future tasks is indicative of preparation for future demands in any context. The anticipatory tendencies of proactive individuals signal preparedness for future circumstances. From a career motivation perspective (London \& Noe, 1997), an employee high in proactive personality who participates in career enhancing activities will acquire knowledge 
and valued skills which may support their movement across organizational boundaries. This means the proactive employee will be more likely to leave their job to apply their new skills in a new environment. Alternatively, a person who is low in proactive personality and engages in a developmental activity may be doing so in response to a recent demand within their organizations. Thus, their participation would prepare them to remain with their organizations, and the implied benefit of their recent growth would be afforded to their current circumstances rather than proactively preparing for the achievement of future-focused career goals.

If one's own discretionary participation in developmental and career enhancing activities is viewed as a proxy for career commitment, Vandenberghe and Ok's (2011) previous research showing that career commitment was positively (negatively) related to turnover intentions for those high (low) in proactive personality further supports the idea that participation in developmental activities interacts with proactive personality to predict the likelihood of voluntary turnover. The resiliency and insight components of career motivation theory combined with the reactive/proactive distinction inherent by definition of proactive personality, suggest that participation in developmental activities moderates the relation between proactive personality and voluntary turnover. That is, combinations of proactivity/reactivity and participation/non-participation may predict whether employees stay or leave. Specifically, highly proactive employees who engage in developmental activities will be more likely to turnover and employees lower in proactive personality will be more likely to stay.

Recall that Vandenberghe and Ok (2011) identified this same directional pattern of interaction between career commitment and proactive personality to predict job embeddedness. This suggests that job embeddedness theory (Mitchell et al., 2001) can also explain the moderating influence of participation in career enhancing activities on the relation between 
proactive personality and whether individuals stay or leave their organization. The constituent elements of job embeddedness theory help to explain this probable interaction. For instance, proactive employees may participate in developmental activities to acquire valued skills and knowledge and become attractive to external organizations. Therefore, the development of new skills combined with the career commitment of proactive individuals justify the breakage of links and the sacrifices made when leaving an organization in an effort to find and create environments more fit to their skills and interests (Seibert et al., 2001). Because a proactive individual who is committed to their career would be more inclined to make such sacrifices to create a better fit elsewhere, they would also be less likely to experience strong organizational linkages or strong apprehension about making sacrifices, two components that typically serve to embed individuals within their jobs. Consider, again, that proactive individuals are likely to hold protean and boundaryless mindsets (Briscoe et al., 2006; Uy et al., 2015) and have high career initiative (Fuller \& Marler, 2009; Seibert et al., 2001). Their openness to mobility as a means of self-managing their careers suggests that these individuals are likely to participate in developmental activities to proactively enhance their employability before making a shift between organizations.

If individuals with a proactive disposition have low participation in developmental activities, it may signal that their current skills and knowledge are well matched with their role. Thus, this high degree of fit would embed them within their organization making it likely they would stay rather than turnover. Similarly, from a career motivation perspective, if a proactive individual does not participate in career enhancing activities, it may signal that they are satisfied with their fit with their current role. As such, they would be unlikely to voluntarily turnover in 
search of alternative opportunities. It could also mean that proactive individuals attempt to change their environment to create a fit before actively preparing to leave the organization.

Therefore, the self-managed nature of protean and boundaryless careers combined with the strong career motivation and tendency of proactive individuals to prepare for the future suggests that their participation in career enhancing activities indicates preparation for the proactive pursuit of new employment opportunities, leading to their voluntary turnover. Conversely, if proactive individuals do not engage in career enhancing activities, they may already experience a strong fit within their current organizations, and their subsequent embeddedness would reduce their likelihood of turnover. Thus, the proposed study expects that participation in developmental activities will moderate the relation between proactive personality and voluntary turnover in this manner.

Hypothesis 5. Participation in developmental activities will moderate the relation between proactive personality and voluntary turnover such that the relationship will be (a) positive when participation is high and (b) negative when participation is low.

Perceived career opportunities as a moderator. Perceived career opportunities capture the degree to which employees believe they can achieve their work-related goals and aspirations within their current organizations (Kraimer et al., 2011). The development of the construct is rooted in London's (1993) career motivation theory, delineating career resilience, insight, and identity as critical factors that drive employee's work decisions and behaviors. Kraimer et al. (2011) identified PCO as a moderator of the relation between organizational support for development and voluntary turnover. Results showed that organizational support for development was positively related to probability of turnover when PCO was high, but negative when PCO was low. In essence, if employees thought that their organization supported their 
development, they stayed with their organizations but only when they perceived intraorganizational career opportunities. Even when employees thought their organization supported their development, they left if they did not perceive sufficient career opportunities at their current organization. When forming their hypotheses, the authors originally highlighted the mixed findings regarding the relation between organizational support for development and turnover, suggesting PCO as a contextual variable that would clarify the nature of this relationship (Kraimer et al., 2011). While organizational support for development is not a variable of interest in the current study, these results show that employee's perceptions of the availability of internal opportunities that align with their interests did, in fact, provide contextual information that elucidated an otherwise uncertain relationship between development support and turnover.

Similarly, research describing how proactive personality is related to turnover is also highly variable, showing mixed findings within the relatively small body of literature surrounding this relationship (Allen et al., 2005; Chung-Yan \& Butler, 2011; Joo et al., 2015; Trifiletti et al., 2009; Vandenberghe \& Ok, 2011; Wang et al., 2011; Wang et al., 2014; Yang et al., 2011). Due to the relevance of PCO to the pursuit and attainment of career goals and interests, it is likely that the relationship between proactive personality and the decision to stay or leave one's organization is contingent upon perceptions of internal career opportunities. A small but developing body of literature supports the role of $\mathrm{PCO}$ as a contextual condition to understanding the staying behaviors of proactive employees.

The probable nature of the relation between $\mathrm{PCO}$ and voluntary turnover decisions has already been discussed, as previous research has identified negative relations between PCO and turnover intentions (Kraimer et al., 2011) and between perceived growth opportunities and turnover (Allen et al., 2003). Additionally, a positive association between proactive personality 
and perceived career opportunities is likely due to the tendency of proactive individuals to seek and create environments (Bateman \& Crant, 1993; Erdogan \& Bauer, 2005) that are congruent with their career goals (Seibert et al., 1999). Proactive individuals who are motivated with high career resilience, insight, and identity may be more sensitive to opportunities within their environments that provide cues about the fit with their career goals and values.

Thus, if individuals with proactive dispositions perceive career opportunities within their organizations that align with their career goals and interests, they will be more likely to remain within their organization to pursue their goals, thereby reducing voluntary turnover. Alternatively, if individuals with proactive dispositions do not perceive opportunities to pursue their career goals within their organization, they will be more likely than their non-proactive counterparts to actively seek alternate opportunities outside of their organizations to fulfill such interests. This is attributable to the fact that proactive individuals actively scan their environments to search for opportunities that serve their career goals (Vandenberghe \& Ok, 2011); and, if those opportunities are not available in their current organization, it may result in the turnover of proactive employees if they believe another organization will provide opportunities to accomplish their career goals (Kraimer et al., 2011). In essence, in the case of low fit between an employee's career goals and career opportunities within their organization, proactive individuals will be more likely to voluntarily turnover and seek alternate opportunities to enhance the fit between individual goals and organizational opportunities. Reduced fit between individual career goals and organizational opportunities (i.e., low PCO) means that employees will not experience the fit required to embed (Mitchell et al., 2001) them within their organizations. Because proactive employees are likely to take steps to create a fit within their environments, they will be more likely to voluntary turnover in the case of low PCO. 
As previously discussed, Wang et al. (2014) identified a negative relation between proactive personality and perceptions of job content plateaus. Job content plateaus are the conceptual juxtaposition of perceived career opportunities in that the perception that one's job lacks sufficient challenge and is "stale" may simultaneously indicate a lack of perceived career opportunities (i.e., high plateau is parallel to low $\mathrm{PCO}$ ). Because, if an individual did perceive career opportunities within their organizations, they would not concurrently perceive a plateau which directly contrasts the notion of movement or growth. Conceptualizing the parallels between plateau and perceived opportunity in this way, Wang et al.'s (2014) findings would suggest that proactive personality is positively related to perceived career opportunities. In addition to the relation between job content plateaus and proactive personality, Wang et al. (2014) also examined the moderating role of proactive personality on the relation between job content plateau and turnover intentions. Proactive personality significantly moderated this relationship. The positive relationship between plateaus and turnover intentions was stronger for individuals with high proactive personality compared to those who were less proactive. This finding suggests that when one's career is perceived to be stagnant in their current organization they will be more likely to consider leaving their organization; and, further, that this relationship is even stronger for proactive employees. When this stagnancy or "staleness" of the job, as Wang et al. (2014) refer to it, is viewed in light of its converse (i.e., mobility, activity, or opportunity), these findings imply that if proactive employees do not perceive career opportunities within their organizations, their turnover intentions would increase. The authors suggest that to avoid the voluntary turnover of proactive employees, organizations need to provide more attention and career opportunities when these employees are experiencing career plateaus (Wang et al., 2014). 
In a similar fashion, Bedeian et al. (1991) found that an orientation towards career commitment interacted with the availability of career growth opportunities to predict turnover intentions such that the relation between growth opportunities and turnover intentions was negative for employees with higher career commitment. Their results indicate that a lack of career growth opportunities will prompt career-committed individuals to consider leaving their organization (Bedeian et al., 1991). Given the tendency of proactive individuals to be highly committed to their careers (Fuller \& Marler, 2009; Seibert et al., 1999; Vandenberghe \& Ok, 2011), these results also support the idea that PCO will moderate the relation between proactive personality and turnover such that proactive individuals will change their environment if it is the difference between creating a better fit to pursue their career goals and interests.

Beyond career motivation and job embeddedness, the likelihood of this moderated relationship can also be explained by social exchange theory (Blau, 1964). Researchers have used social exchange theory to suggest that employees are likely to exchange their commitment for their employer's support (Cropanzano \& Mitchell, 2005). Thus, if an employee perceives the provision of career opportunities in an organization as supporting their career goals, they may reciprocate (Gouldner, 1960) this exchange via their commitment to the organization. By the same argument that individuals with a proactive disposition may be more aware of the perceive career opportunities in their environment, this increased perception may lead to increased feelings of obligation and the need to reciprocate the affordance of such career opportunities by staying with their organization. Therefore, career motivation, job embeddedness, and social exchange theories all suggest that that the decisions of proactive individuals to turnover or to stay may be contingent upon their perceptions of intra-organizational career opportunities. 
Hypothesis 6. Perceived career opportunities will moderate the relation between proactive personality and voluntary turnover such that the relationship will be (a) positive when perceived career opportunities are low and (b) negative when perceived career opportunities are high. 


\section{CHAPTER III: RESEARCH DESIGN}

\section{Method}

\section{Participants}

The data used for analysis was archival and provided only minimal demographic information to maintain confidentiality regarding participant information. Data was collected from 295 job incumbents of a multinational European organization. Full data were available for all participants. Of these participants, 62\% (183) were female with an average age of 31.18 years old $(S D=4.55)$. Based on demographic information received from $H R$, the sample appeared to be representative of employees within the organization. At the second point of data collection, $12 \%$ (35) of participants had voluntarily turned over while $88 \%$ (260) remained within the organization.

\section{Measures}

Proactive personality. Proactive Personality was measured using the shortened 10-item version of Bateman and Crant's (1993) 17-item Proactive Personality Scale (PPS). Seibert et al. (1999) created the 10-item PPS by selecting the 10 items with the largest factor loadings that had been reported in three of Bateman and Crant's (1993) previous studies. Sample items include "I am constantly on the lookout for new ways to improve my life", "I love being a champion for my ideas, even against others' opposition", and "I can spot a good opportunity long before others can”. Participants responded to each item on a 7-point Likert scale $(1=$ strongly disagree to $7=$ strongly agree). The average of the 10 items were computed to create a PPS scale score.

Seibert et al. (1999) reported Cronbach's alpha for the 10-item PPS of .86, which is comparable to Cronbach's alpha for the 17-item scale of .88 reported in their validation study. More recently, Fuller and Marler's (2009) meta-analysis included 109 studies that utilized PPS 
measures of varying lengths. The average Cronbach's alpha coefficient for the 30 samples using the 17 -item PPS was .86 with a range from .73 to .91 . The average Cronbach's alpha coefficient for the 54 samples using the 10 -item PPS was .86 with a range from .77 to .94 . Therefore, it is evident that Seibert et al.'s (1999) shortened measure of proactive personality consistently demonstrates comparable internal consistency reliabilities to Bateman and Crant's (1993) original 17-item scale. The average alphas of the 4 and 6-item versions of the PPS assessed in Fuller and Marler's (2009) meta-analysis were .78 and .76, respectively. This suggests that the shortened 10-item PPS does not sacrifice reliability in comparison to the original scale, but the extremely truncated 4 and 6-item versions of the PPS do. Further, Seibert et al. (1999) also reported an extremely strong correlation of .96 between the 10 -item and 17 -item version of the PPS, which further solidifies the 10 -item PPS as a valid alternative to the original scale. In fact, the 10-item PPS is the most frequently used version of the PPS (Crant, Hu, \& Jiang, n.d.).

Developmental activities. Similar to Kraimer et al. (2011), employees were asked to indicate the extent to which "you have participated in the following career development activities while employed by [company name]. Compare yourself to other colleagues in your company.” (p. 492) in relation to five items about developmental activities. The items were "I attended (online or in person) training/workshops designed to develop my interpersonal/managerial skills", "I attended (on-line or in person) training/workshops designed to develop my technical skills", "I attended career planning/management workshops", "I took different job assignments within the company", and "I took courses in college or continuing education credits". Participants responded to each item on a 7 -point Likert scale $(1=$ not at all to $7=$ a very large extent $)$.

Analogous to the method used by Kraimer et al. (2011), these items were developed after consulting with HR managers and share a large degree of similarity with the Kraimer et al. 
(2011) items for participation in formal developmental activities (p. 492). Kraimer et al. (2011) included three items about workshops/training to develop technical skills, managerial skills, and career planning workshops $(\propto=.64)$, two items about job rotation into different divisions and different functional areas within the company $(\propto=.79)$, and one item regarding educational courses that qualified for tuition reimbursement. Similarly, the items within the proposed study include three items about workshops and training, one about job rotation, and one about continuing education. Because the proposed study does not include separate hypotheses about specific types of developmental activities, the average of these five items were used to create an overall developmental activity score for each participant.

Perceived career opportunities. PCO was measured using the 3-item scale developed by Kraimer et al. (2011). In a pilot study, the authors developed 4-items to measure PCO and conducted a principal axis factor analysis to assess the distinctiveness of PCO from related constructs like perceived organizational support (POS), perceived career plateau, and satisfaction with promotions. The results of this analysis revealed three factors; the first two included combinations of items measuring POS, perceived career plateau, and satisfaction with promotions and the third factor included three of the four PCO items. The fourth PCO item did not load onto any factor above .30 and thus was removed from the PCO scale. The remaining three items each had factor loadings above .64, and a Cronbach's alpha of .84 in the pilot study.

Kraimer et al. (2011) also established convergent and discriminant validity of the PCO construct, showing that $\mathrm{PCO}$ was negatively correlated with perceived career plateau $(r=-.45, p$ $<.01)$ and positively correlated with POS $(r=.40, p<.01)$ and satisfaction with promotions $(r=$ $.43, p<.01)$ as they expected. Therefore, the authors provided sufficient evidence of convergent and discriminant validity to warrant the use of the PCO measure in their study. The authors 
reported a Cronbach's alpha of .78 when used within their primary study. The final three items of the PCO scale are "There are career opportunities within [Company] that are attractive to me", "There are job opportunities available within [Company] that are of interest to me", and "[Company] offers many job opportunities that match my career goals". Participants responded to each item on a 7 -point Likert scale $(1=$ strongly disagree to $7=$ strongly agree $)$, and their responses were averaged to create a scale score for PCO.

Voluntary turnover. Employee turnover was assessed via organizational records 12 months after the initial surveys were administered. Participants were coded as 0 if they stayed with the organization $(n=260)$ and 1 if they voluntarily chose to leave the organization $(n=35)$.

\section{Procedure}

Employees' participation in the study was voluntary. Participants completed paper-andpencil surveys and placed them in boxes upon completion to maintain anonymity. After all surveys were collected, the boxes were sealed and picked up by researchers. 


\section{CHAPTER IV: ANALYSES AND RESULTS}

\section{Summary of Analyses}

The means, standard deviations, correlations, and reliabilities (Cronbach's alphas), among the study variables can be found in Table 1. Measures of proactive personality $(\alpha=.86)$, participation in developmental activities $(\alpha=.82)$, and perceived career opportunities $(\alpha=.94)$ each showed high levels of internal consistency reliability. Research Question 1 investigating the relation between proactive personality and voluntary turnover was tested using a point bi-serial correlation. Hypotheses 1 and 3 were tested by examining the zero-order correlation coefficients among proactive personality, participation in developmental activities, and PCO. Due to the dichotomous nature of the dependent variable, multiple binary logistic regression was used to test Hypotheses 2-6 examining various predictors of voluntary turnover. One logistic regression model tested the direct effect of participation in developmental activities as well the interaction between participation in developmental activities and proactive personality in predicting

turnover, addressing Hypotheses 2 and 5, respectively. A second logistic regression model tested the direct effect of PCO and the interaction between $\mathrm{PCO}$ and proactive personality in predicting turnover, testing Hypotheses 4 and 6, respectively. In each model, independent variables were entered in the first step. In the second step, the multiplicative interaction term between proactive personality and the moderator was entered. Variables in the interaction terms were not centered, as doing so is more a choice of "interpretational convenience than a necessity" (Hayes \& Matthes, 2009, p. 925).

Neither age, $r=.06, p=.326$, nor gender, $r=.08, p=.160$, were significantly correlated with proactive personality. Additionally, gender and age were initially entered into each regression analysis but did not significantly affect the resulting statistics, thus, they are not 
included in the ensuing results and interpretation. An analysis of the distributions of the proactive personality, participation in developmental activities, and perceived career opportunities variables revealed that each were normally distributed with minimal skewness and kurtosis values within \pm 1 (the suggested acceptable range is \pm 2 ).

\section{Results of Correlations}

The present study offered Research Question 1 inquiring about the nature of the linear relation between proactive personality and voluntary turnover. As Table 1 shows, proactive personality and voluntary turnover were not significantly correlated $(r=.04, p=.541)$. An examination of the zero-order product-moment correlation coefficients shows proactive personality was positively correlated with participation in developmental activities $(r=.28, p<$ .001 ) as expected, providing full support for Hypothesis 1 . The zero-order correlation between proactive personality and perceived career opportunities was non-significant $(r=-.04, p=.51)$, thus Hypothesis 3 was not supported. 
Table 1

Correlations and Descriptive Statistics $(N=295)$

\begin{tabular}{lccccccc}
\hline Variable & $\mathrm{M}$ & $\mathrm{SD}$ & 1 & 2 & 3 & 4 & 5 \\
\hline 1. Age & 31.18 & 4.55 & -- & & & & \\
2. Gender & 1.62 & .49 & .05 & -- & & & \\
3. Proactive Personality & 5.28 & .68 & .06 & .08 & $(.86)$ & & \\
4. Developmental Activities & 4.77 & 1.04 & -.02 & .10 & $.28^{* *}$ & $(.82)$ & \\
5. Perceived Career Opportunities & 5.02 & 1.41 & .04 & -.08 & -.04 & -.10 & $(.94)$ \\
6. Turnover & .12 & .32 & .04 & -.04 & .04 & $-.16^{*}$ & -.01 \\
\hline
\end{tabular}

Note. Internal consistency values (Cronbach's $\alpha$ ) are listed along the diagonal in parentheses. Gender: $1=$ male, $2=$ female. Turnover: $0=$ stayed, $1=$ left. ${ }^{*} p<.01,{ }^{* *} p<.001$.

\section{Results of Multiple Binary Logistic Regression Analysis}

\section{Participation in Developmental Activities and Voluntary Turnover}

Hypothesis 2 proposed two competing hypotheses predicting participation in developmental activities would either (a) negatively or (b) positively predict voluntary turnover. These competing hypotheses were tested using a multiple binary logistic regression analysis. Proactive personality and participation in developmental activities were entered in the first step of the analysis. This step was significant in comparison to a constant-only model. Rather than examine sums-of-squares when assessing models in ordinary least squares regression, measures of deviance must be examined when comparing logistic regression models (Cohen, Cohen, West, \& Aiken, 2003). When examining the deviance, or the "badness-of-fit", the model with significantly lower deviance is considered a better fit (Cohen et al., 2003). Table 2 displays the 
deviance, or log likelihood $(-2 L L)$, between the constant-only model and the model considering the two main effects of proactive personality and participation in developmental activities. Results show the more complete model including proactive personality and participation in developmental activities (Block 1) has significantly less deviance, $-2 L L=206.47, \chi^{2}(2, N=295)$ $=8.42, p=.01$, Nagelkerke $\mathrm{R}^{2}=.05$, than the constant-only model (Block 0$)$, suggesting the more complete model is a better predictor of voluntary turnover. Rather than a traditional $\mathrm{R}^{2}$ value, Nagelkerke's pseudo $\mathrm{R}^{2}$ was used to determine the predictive improvement between the two models due to the nature of logistic regression (Kraimer et al., 2011).

\section{Table 2}

Deviance Statistics for Moderated Logistic Regression Analysis Results of Proactive Personality and Participation in Developmental Activities Predicting Voluntary Turnover

\begin{tabular}{|c|c|c|c|c|c|c|}
\hline \multirow[b]{2}{*}{ Block } & \multirow[b]{2}{*}{ Predictor Variables } & \multicolumn{2}{|c|}{$\underline{\text { Model Total }}$} & \multicolumn{2}{|c|}{$\begin{array}{l}\text { Difference from } \\
\text { Previous Block }\end{array}$} & \multirow[b]{2}{*}{$\begin{array}{l}\text { Nagelkerke } \\
\mathrm{R}^{2}\end{array}$} \\
\hline & & $-2 L L$ & df & $-2 L L$ & $\mathrm{df}$ & \\
\hline 0 & Intercept & 215.11 & 0 & & & \\
\hline 1 & $\begin{array}{l}\text { Proactive Personality, } \\
\text { Developmental Activities }\end{array}$ & 206.47 & 2 & $8.64 * *$ & 2 & .05 \\
\hline 2 & $\begin{array}{l}\text { Proactive Personality } \times \\
\text { Developmental Activities }\end{array}$ & 199.59 & 3 & $6.88 * *$ & 1 & .10 \\
\hline
\end{tabular}

Note. $N=295 . * p<.05 . * * p \leq .01 . L L=\log$ likelihood. 
Within this first step of the regression analysis, participation in developmental activities was the only significant predictor of voluntary turnover, $B=-.47, S E=.16, \operatorname{Exp}(B)=.63, p=$ .004. All coefficients and their confidence intervals can be found in Table 3. An $\operatorname{Exp}(B)$ value of less than 1.0 indicates a negative relationship with the outcome variable while a value above 1.0 indicates a positive relationship. Therefore, participation in developmental activities is a significant negative predictor of voluntary turnover, supporting Hypothesis $2 \mathrm{a}$ and ruling out Hypothesis $2 \mathrm{~b}$ of the two competing hypotheses. This indicates that when employees participate in more developmental activities, their probability of turnover decreases. More specifically, for each unit increase in developmental activity participation, likelihood of turnover decreases by a multiplicative term of .63; that is, employees are $37 \%$ less likely to voluntarily turnover. 
Table 3

Moderated Logistic Regression Analysis Predicting Voluntary Turnover with Proactive Personality and Participation in Developmental Activities

\begin{tabular}{|c|c|c|c|c|c|}
\hline Variable & $B$ & $\mathrm{SE} B$ & $\operatorname{Exp}(B)$ & $\begin{array}{c}95 \% \\
\text { Lower C.I. }\end{array}$ & $\begin{array}{c}95 \% \\
\text { Upper C.I. }\end{array}$ \\
\hline \multicolumn{6}{|l|}{ Step $1^{\mathrm{a}}$} \\
\hline Proactive Personality & .33 & .27 & 1.39 & .82 & 2.56 \\
\hline Developmental Activities & $-.47 * *$ & .16 & .63 & .46 & .86 \\
\hline \multicolumn{6}{|l|}{ Step $2^{b}$} \\
\hline Proactive Personality & $-2.39 *$ & 1.11 & .09 & .01 & .81 \\
\hline Developmental Activities & $-4.00 * *$ & 1.38 & .02 & $<.01$ & .27 \\
\hline $\begin{array}{l}\text { Proactive Personality } \times \\
\text { Developmental Activities }\end{array}$ & $.64 * *$ & .25 & 1.89 & 1.16 & 3.07 \\
\hline
\end{tabular}

Note. $N=295 . B=\log$ odds; $\mathrm{SE} B=$ standard error of $\log$ odds; $\operatorname{Exp}(B)=$ odds ratio. ${ }^{*} p<.05$. ${ }^{* *} p \leq .01 .{ }^{\mathrm{a}} \chi^{2}(2, N=295)=8.42, p=.01$. Nagelkerke $\mathrm{R}^{2}=.05 .{ }^{\mathrm{b}} \chi^{2}(1, N=295)=6.88, p=.01$. Nagelkerke $\Delta R^{2}=.04$.

Building on Block 1 of this logistic regression model, the interaction term between proactive personality and participation in developmental activities was entered in the second step of the model to test Hypothesis 5. This second step (Block 2) significantly improved the predictiveness of the model, $\Delta R^{2}=.04$, resulting in a more complete model with significantly less deviance than the former block, $-2 L L=199.58, \chi^{2}(3, N=295)=15.30, p=.002$, Nagelkerke $\mathrm{R}^{2}=.10$. The complete model explained $9.8 \%$ of the variance in voluntary turnover. These deviance comparisons are also displayed in Table 3 . The proactive personality $\times$ participation in developmental activities interaction term was a significant predictor of voluntary turnover, $B=$ 
$.64, S E=.25, \operatorname{Exp}(B)=1.89, p=.010$. Table 3 displays the confidence intervals for the regression coefficients. Therefore, participation in developmental activities significantly moderated the relation between proactive personality and turnover, tentatively supporting Hypothesis 5. The simple slopes were examined to determine the direction of the interaction.

Table 4 shows the proactive personality-voluntary turnover relationship at different levels of participation in developmental activities. A graph of the relationship between proactive personality and the probability of turnover as a function of participation in developmental activities can be seen in Figure 2. Hypothesis 5 predicted participation in developmental activities would moderate the relationship between proactive personality and turnover such that the relationship would be (a) negative when participation in developmental activities was low and (b) positive when participation was high. Figure 2 shows the relation between proactive personality and turnover was slightly negative, though mainly constant at low levels participation in developmental activities, failing to provide support for Hypothesis 5a. However, as expected, proactive personality was positively related to voluntary turnover when participation in developmental activities was high. When participation in developmental activities increases by one unit, the positive relationship between proactive personality and turnover increases by a multiplicative factor of 1.89 ; thus, Hypothesis $5 \mathrm{~b}$ was supported. 
Table 4

Proactive Personality-Voluntary Turnover Relationship at Different Levels of Participation in Developmental Activities

\begin{tabular}{ccc|ccc}
\hline & \multicolumn{2}{c|}{ Low Participation } & \multicolumn{3}{c}{ High Participation } \\
Proactive & Log odds & $P(Y=1 \mid X)$ & $\begin{array}{c}\text { Proactive } \\
\text { Personality }\end{array}$ & Log odds & $P(Y=1 \mid X)$ \\
Personality & -1.60 & .17 & 1 & -8.60 & $<.01$ \\
1 & -1.61 & .17 & 2 & -7.29 & $<.01$ \\
2 & -1.63 & .16 & 3 & -5.98 & $<.01$ \\
4 & -1.64 & .16 & 4 & -4.67 & .01 \\
5 & -1.66 & .16 & 5 & -3.35 & .03 \\
6 & -1.67 & .16 & 6 & -3.35 & .11 \\
7 & -1.69 & .16 & 7 & -3.35 & .33 \\
\hline
\end{tabular}

Note. $P(Y=1 \mid X)$ represents the probability of voluntarily turning over at a given level of proactive personality. Low and high values of participation in developmental activities represent one standard deviation below and above the mean, respectively.

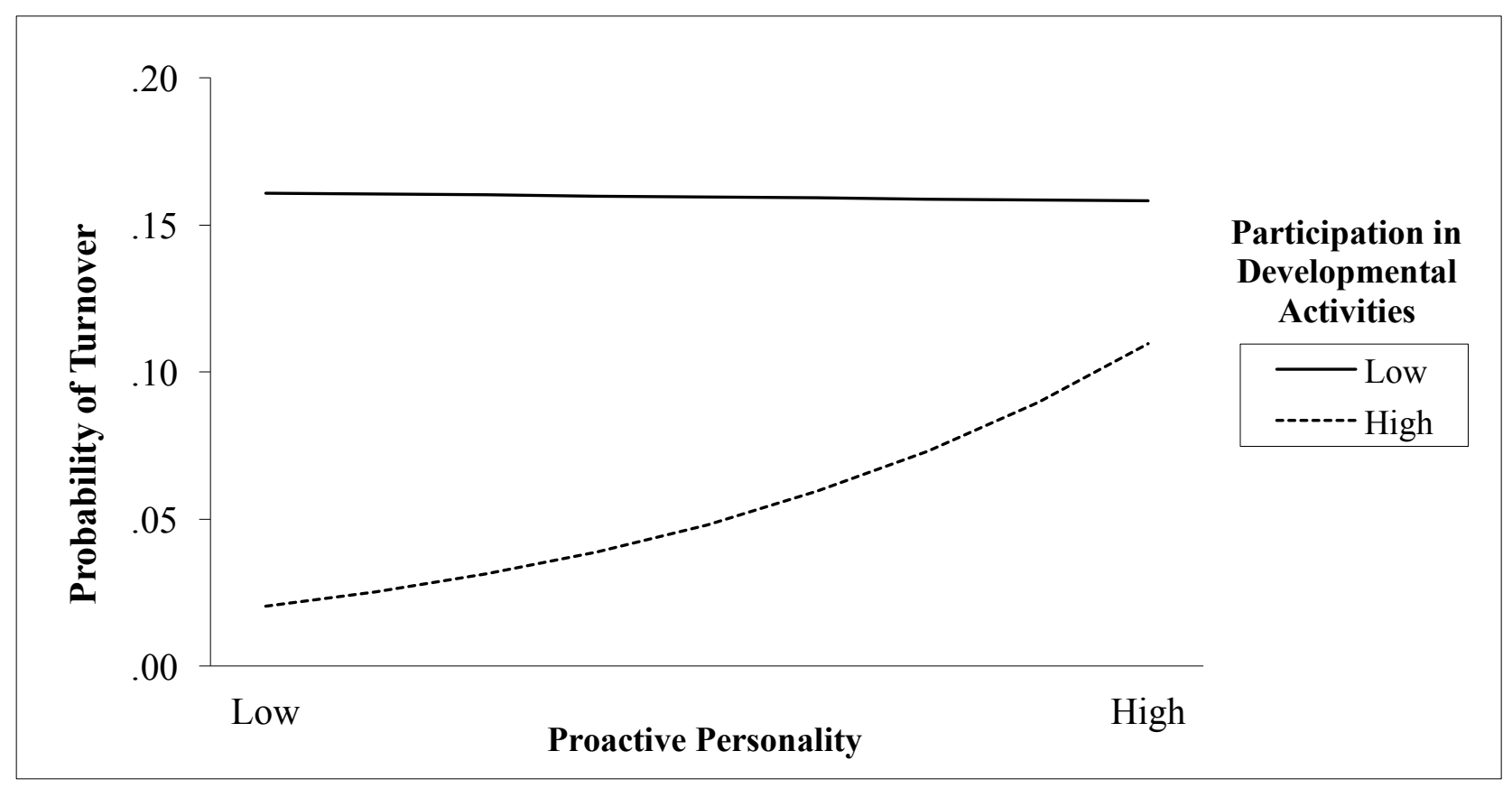

Figure 2. Plot of two-way logistic regression interaction between proactive personality and participation in developmental activities. 


\section{Perceived Career Opportunities and Voluntary Turnover}

Hypothesis 4 predicted perceptions of available career opportunities would negatively predict voluntary turnover. This hypothesis was tested using a multiple binary logistic regression analysis. Proactive personality and PCO were entered in the first step of the analysis. Again, when examining the deviance, or "badness-of-fit", a model with significantly lower deviance is considered a better fit (Cohen et al., 2003). Table 5 displays the deviance, or log likelihood ($2 L L)$, between the constant-only model (Block 0 ) and the model considering the main effects of proactive personality and PCO (Block 1). Results show that the model including proactive personality and PCO (Block 1) did not have significantly less deviance than the constant-only model (Block 0), $-2 L L=224.49, \chi^{2}(2, N=295)=.39, p=.82$, Nagelkerke $\mathrm{R}^{2}=.003$. Furthermore, neither proactive personality nor PCO had significant regression coefficients. Confidence intervals around the coefficients in this analysis can be found in Table 6. This suggests that adding proactive personality and PCO to the model did not significantly improve predictions of the probability of voluntary turnover. Therefore, PCO was not a significant predictor of voluntary turnover in the regression model and Hypothesis 4 was not supported.

Building on Block 1 of this logistic regression model, the interaction term between proactive personality and PCO was entered in the second step. This second step (Block 2) had significantly less deviance than Block, $-2 L L=209.38, \chi^{2}(1, N=295)=5.12, p=.024$, Nagelkerke $\mathrm{R}^{2}=.04$, indicating a better fit. The full model trended towards significance, $\chi^{2}(3, N$ $=295)=5.51, p=.14$. Full deviance statistics are displayed in Table 5. Within Block 2, the proactive personality $\times$ PCO interaction term was a significant predictor of voluntary turnover, $B$ $=-.46, S E=.21, \operatorname{Exp}(B)=.64, p=.03$, as hypothesized. All regression coefficients for the moderated logistic regression can be found in Table 6 . 
Table 5

Deviance Statistics for Moderated Logistic Regression Analysis Results of Proactive Personality and Perceived Career Opportunities Predicting Voluntary Turnover

\begin{tabular}{|c|c|c|c|c|c|c|}
\hline \multirow[b]{2}{*}{ Block } & \multirow[b]{2}{*}{ Predictor Variables } & \multicolumn{2}{|c|}{$\underline{\text { Model Total }}$} & \multicolumn{2}{|c|}{$\begin{array}{l}\text { Difference from } \\
\text { Previous Block }\end{array}$} & \multirow[b]{2}{*}{$\begin{array}{c}\text { Nagelkerke } \\
\mathrm{R}^{2}\end{array}$} \\
\hline & & $-2 L L$ & $\mathrm{df}$ & $-2 L L$ & $\mathrm{df}$ & \\
\hline 0 & Intercept & 214.88 & 0 & & & \\
\hline 1 & Proactive Personality, PCO & 214.49 & 2 & .39 & 2 & $<.01$ \\
\hline 2 & Proactive Personality $\times \mathrm{PCO}$ & 209.38 & 3 & $5.12 *$ & 1 & .04 \\
\hline
\end{tabular}

Table 6

Moderated Logistic Regression Analysis Predicting Voluntary Turnover with Proactive Personality and Perceived Career Opportunities

\begin{tabular}{|c|c|c|c|c|c|}
\hline Variable & $B$ & $\mathrm{SE} B$ & $\operatorname{Exp}(B)$ & $\begin{array}{c}95 \% \\
\text { Lower C.I. }\end{array}$ & $\begin{array}{c}95 \% \\
\text { Upper C.I. }\end{array}$ \\
\hline \multicolumn{6}{|l|}{ Step $1^{\mathrm{a}}$} \\
\hline Proactive Personality & .16 & .27 & 1.18 & .70 & 1.98 \\
\hline $\mathrm{PCO}$ & -.02 & .13 & .90 & .77 & 1.26 \\
\hline \multicolumn{6}{|l|}{ Step $2^{b}$} \\
\hline Proactive Personality & $2.54 *$ & 1.13 & 12.74 & 1.40 & 115.93 \\
\hline $\mathrm{PCO}$ & $2.44 *$ & 1.33 & 11.47 & 1.26 & 104.14 \\
\hline Proactive Personality $\times \mathrm{PCO}$ & $-.45^{*}$ & .21 & .64 & .43 & .95 \\
\hline
\end{tabular}


Therefore, PCO significantly moderated the relation between proactive personality and turnover, tentatively supporting Hypothesis 6 . The simple slopes were examined to determine if the interaction proceeded in the hypothesized direction. Table 7 shows the relation between proactive personality and voluntary turnover at different levels of PCO. The graph of the relationship between proactive personality and the probability of turnover as a function of PCO can be seen in Figure 3.

Table 7

Proactive Personality-Voluntary Turnover Relationship at Different Levels of Perceived Career Opportunities

\begin{tabular}{ccc|ccc}
\hline & Low $P C O$ & & \multicolumn{3}{|c}{ High $P C O$} \\
Proactive \\
Personality & Log odds & $P(Y=1 \mid X)$ & $\begin{array}{c}\text { Proactive } \\
\text { Personality }\end{array}$ & Log odds & $P(Y=1 \mid X)$ \\
\hline 1 & -6.00 & 0.00 & 1 & -0.42 & 0.40 \\
2 & -5.10 & 0.01 & 2 & -0.80 & 0.31 \\
3 & -4.20 & 0.01 & 3 & -1.18 & 0.24 \\
4 & -3.30 & 0.04 & 4 & -1.56 & 0.17 \\
5 & -2.40 & 0.08 & 5 & -1.94 & 0.13 \\
6 & -1.50 & 0.18 & 6 & -2.32 & 0.09 \\
7 & -0.61 & 0.35 & 7 & -2.70 & 0.06 \\
\hline
\end{tabular}

Note. $P(Y=1 \mid X)$ represents the probability of voluntarily turning over at a certain level of proactive personality. $\mathrm{PCO}=$ Perceived Career Opportunities. Low and high values of PCO represent one standard deviation below and above the mean, respectively. 
Hypothesis 6 predicted PCO would moderate the relation between proactive personality and turnover such that the relationship would be (a) positive when PCO was low and (b) negative when PCO was high. Figure 3 shows the relation between proactive personality and voluntary turnover was, indeed, positive when PCO was low and negative when PCO was high, fully supporting Hypotheses $6 \mathrm{a}$ and $6 \mathrm{~b}$. When perceptions of career opportunities were low, the probability of highly proactive employees voluntarily turning over increased. Alternatively, when perceived career opportunities were high, the probability of highly proactive employees voluntarily turning over decreased by a multiplicative factor of .64, meaning that for each one unit increase in PCO, proactive individuals were 36\% less likely to turnover. These results support the notion that perceptions of available career opportunities play a significant role in proactive employees' decisions to stay or voluntarily turnover. A full summary of the support of each proposed hypothesis within the present study can be found in Table 8 . 


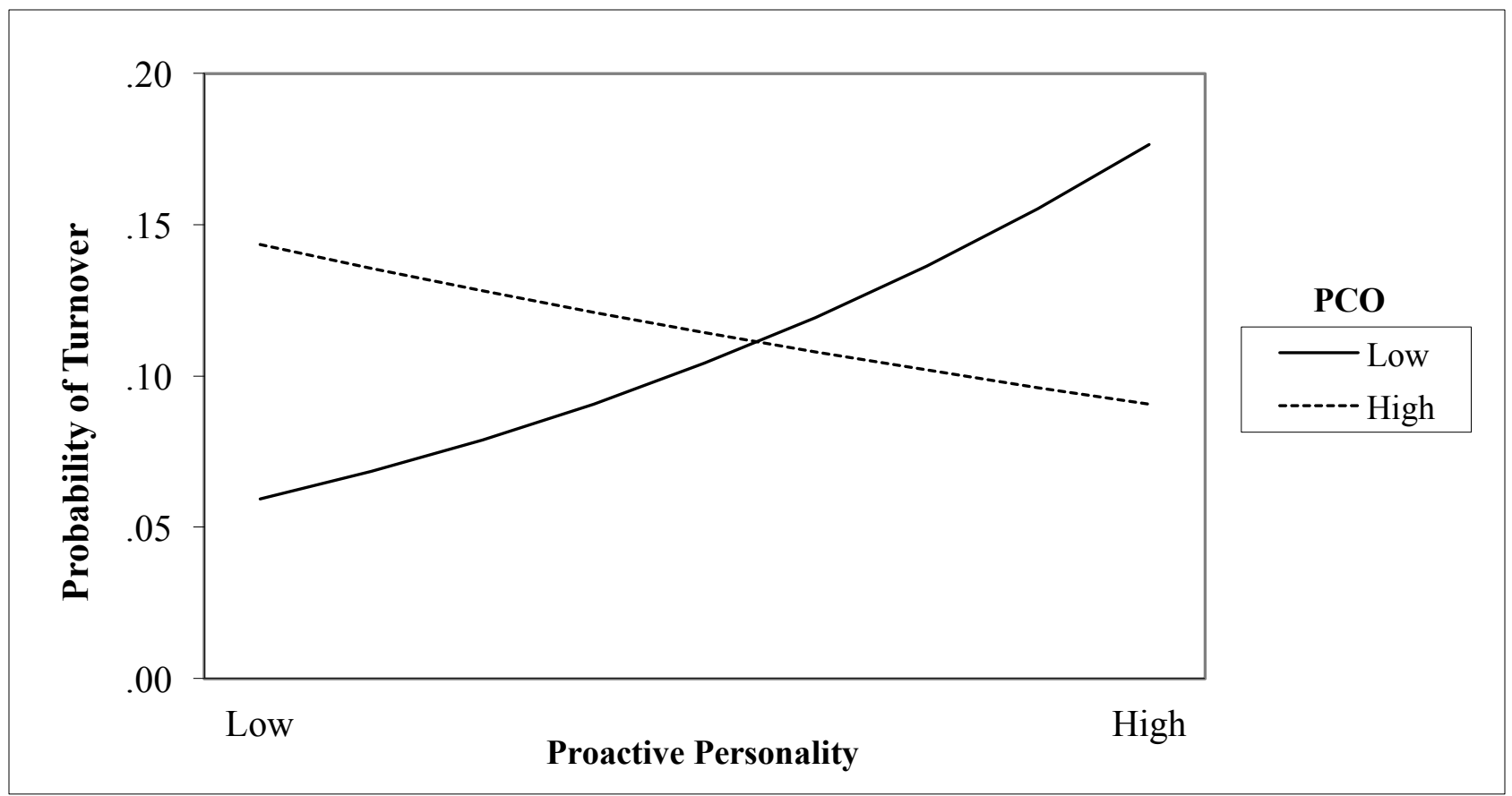

Figure 3. Plot of two-way logistic regression interaction between proactive personality and perceived career opportunities. $\mathrm{PCO}=$ perceived career opportunities. 
Table 8

Summary of Support for Proposed Research Questions and Hypotheses

\begin{tabular}{|c|c|c|}
\hline Hypothesis & & Support \\
\hline RQ 1 & $\begin{array}{l}\text { How is proactive personality directly related to voluntary } \\
\text { turnover? }\end{array}$ & $\begin{array}{l}\text { Non-significant } \\
\text { Correlation }\end{array}$ \\
\hline H 1 & $\begin{array}{l}\text { Proactive personality will be positively related to } \\
\text { participation in developmental activities. }\end{array}$ & Supported \\
\hline $\mathrm{H} 2 \mathrm{a}$ & $\begin{array}{l}\text { Participation in developmental activities will negatively } \\
\text { predict voluntary turnover. }\end{array}$ & Supported \\
\hline $\mathrm{H} 2 \mathrm{~b}$ & $\begin{array}{l}\text { Participation in developmental activities will positively } \\
\text { predict voluntary turnover. }\end{array}$ & Not Supported \\
\hline H 3 & $\begin{array}{l}\text { Proactive personality will be positively related to perceived } \\
\text { career opportunities. }\end{array}$ & Not Supported \\
\hline $\mathrm{H} 4$ & $\begin{array}{l}\text { Perceived career opportunities will negatively predict } \\
\text { voluntary turnover. }\end{array}$ & Not Supported \\
\hline H 5 & $\begin{array}{l}\text { Participation in developmental activities will moderate the } \\
\text { relationship between proactive personality and turnover } \\
\text { such that (a) it will be negative when participation in } \\
\text { developmental activities is low and (b) positive when } \\
\text { participation is high. }\end{array}$ & $\begin{array}{l}\text { a) Not } \\
\text { Supported } \\
\text { b) Supported }\end{array}$ \\
\hline H 6 & $\begin{array}{l}\text { Perceived career opportunities will moderate the } \\
\text { relationship between proactive personality and turnover } \\
\text { such that (a) the relationship will be positive when } \\
\text { perceived career opportunities are low and (b) negative } \\
\text { when perceived career opportunities are high }\end{array}$ & $\begin{array}{l}\text { a) Supported } \\
\text { b) Supported }\end{array}$ \\
\hline
\end{tabular}




\section{CHAPTER V: DISCUSSION}

\section{Summary of Findings}

The purpose of this study was to better understand factors that influence proactive employees' decisions to stay or leave their organizations. Research Question 1 queried the nature of the direct relation between proactive personality and voluntary turnover. Results showed that proactive personality was not significantly correlated with voluntary turnover. In support of Hypothesis 1, proactive personality was found to be significantly positively correlated with participation in developmental activities. However, contrary to expectations, proactive personality was not correlated with PCO, failing to support Hypothesis 3. Within the present study, two competing hypotheses were offered regarding the predictive relationship between participation in developmental activities and voluntary turnover. Hypothesis 2 a suggesting that participation in developmental activities would be a negative predictor of turnover was supported, while Hypothesis $2 \mathrm{~b}$ suggesting it would be a positive predictor was not. Further, participation in developmental activities interacted with proactive personality to predict turnover as hypothesized. Specifically, proactive personality was expected to be negatively correlated to turnover when participation was low, but positively correlated to turnover when participation was high. Results showed that when participation in developmental activities was low, the proactive personality-turnover relationship was constant, so Hypothesis 5a was not supported; however, when participation in developmental activities was high, the relationship between proactive personality and voluntary turnover was positive, as predicted in Hypothesis $5 \mathrm{~b}$. In a second regression analysis, $\mathrm{PCO}$ was expected to be a negative predictor voluntary turnover but the coefficient was not significant, thus Hypothesis 4 was not supported. In the second step of this analysis, the interaction term between PCO and proactive personality was found to be a 
significant predictor of voluntary turnover, as predicted. An examination of this interaction revealed proactive personality was positively related to probability of turnover when PCO was low, but negatively related to turnover when PCO was high, supporting Hypotheses $6 \mathrm{a}$ and $6 \mathrm{~b}$.

\section{General Discussion}

The primary objective of the present study was to better understand the nature of the relation between proactive personality and voluntary turnover as well as to provide a preliminary analysis of the contextual factors that affect this relationship. While proactive personality was not found to be significantly correlated to voluntary turnover, this is not surprising given the highly variable results of previous studies exploring this same relationship (Allen et al., 2005; Chung-Yan \& Butler, 2011; Joo et al., 2015; Trifiletti et al., 2009; Vandenberghe \& Ok, 2011; Wang et al., 2011; Wang et al., 2014; Yang et al., 2011). In fact, the lack of existence of a direct relationship only magnifies the importance of understanding the interactive influence of other variables to distinguish conditions under which proactive personality is related to turnover decisions. The multiple significant interactive effects found in the present study verify that the relation between proactive personality and voluntary turnover is more nuanced than a simple linear correlation.

The significant positive correlation between proactive personality and participation in developmental activities suggests proactive individuals may be more motivated to seek career enhancing activities as a means of proactively managing their own growth and development within the era of protean careers (Briscoe et al., 2006). As previous research suggests, individuals who prioritize work in their lives are more likely to find utility in participating in activities to develop work-relevant skills and knowledge (Hurtz \& Williams, 2009). The negative predictive relationship between participation in developmental activities and voluntary 
turnover provides supporting evidence for the probable influence of job embeddedness theory (Mitchell et al., 2001) in predicting the likelihood of staying. As individuals participate in various career enhancing activities, they gain skills and knowledge that enhance their ability to carry out their current roles. In this sense, increased participation improves the fit between an employee and their position by aligning their skills to those required of the job. This enhanced fit is one way in which an individual may become embedded in their organization, thus reducing their likelihood of voluntary turnover. The negative relationship between developmental activities and voluntary turnover was more prominent for individuals with low proactive personality. That is, as employees participated in more developmental activities their likelihood of turnover generally decreased, but this effect was more pronounced for employees with low levels of proactive personality than for highly proactive employees. This was expected as nonproactive individuals were hypothesized to participate in developmental activities as a reaction to the needs of their role. Additionally, it was hypothesized that highly proactive employees' participation in developmental activities would signal preparations for a career transition by enhancing one's marketability. However, it may be the case that highly proactive individuals participate in developmental activities regardless of whether they intend to stay or leave due to their high career commitment, explaining why participation was a stronger predictor for employees low on proactive personality.

As expected, perceived career opportunities interacted with proactive personality to explain the probability of voluntary turnover. When PCO was low, proactive employees were more likely to voluntarily turnover than employees low on proactive personality. Additionally, when PCO was high, highly proactive employees were more likely to stay. Recall that PCO captures the degree to which employees believe they can achieve their work-related goals and 
aspirations within their current organizations (Kraimer et al., 2011). Additionally, PCO is rooted in London's (1983) career motivation theory, identifying career resilience, insight, and identity as key factors driving employee's work behaviors. This significant interaction term verifies that proactive employees make critical evaluations of their environments regarding the possible fulfillment of their work-related goals and aspirations. For proactive employees who are motivated to pursue such career goals, perceptions of the inability to attain such objectives within their current organizations predicts their likelihood of leaving in hopes of obtaining desired opportunities elsewhere. Conversely, when perceived career opportunities were high, proactive individuals were less likely to turnover. One possible explanation is that leaving one's organization would entail sacrificing those perceived career opportunities, thus the availability of such opportunities fits with their respective career goals. Both fit and sacrifice are two constituent elements that serve to embed employees in their organizations and reduce the likelihood of turnover (Mitchell et al., 2011).

\section{Limitations and Strengths}

One limitation of the current study involves the way participation in developmental activities was measured. No distinction was made between developmental activities provided by or reimbursed by the organization versus those that were self-sought and self-funded. Employees were asked to indicate the extent to which they participated in a number of career development activities "while employed by [company name]" and additionally instructed to compare their selves to other colleagues in their company. Phrasing the question in this way may have provided a narrow frame of reference for employees, with their responses focused on developmental activities that were in some way connected to the organization. For instance, the negative relationship between participation in developmental activities and probability of 
voluntarily turnover could possibly be due to an enhanced sense of organizational commitment due to the organization's support of employee development, especially if education courses were reimbursed by the organization. If participation in developmental activities in the current study was more of an indicator of participation in activities sponsored by the company, then the effects must be interpreted differently. In such a case, the research question becomes more nuanced, deviating from the intended investigation of activities sought out as a means of self-development, moving toward an investigation of organizational support for development and how such support might garner organizational commitment. In summary, while participation in developmental activities was a significant negative predictor of voluntary turnover and interacted with proactive personality to predict turnover, it is not possible to discern whether affective or normative organizational commitment (Allen \& Meyer, 1990) played a role in such predictive effects. Future research is needed to measure the unique effects of organizationally sanctioned activities versus those independent of one's organization. Additionally, it should be noted that due to the correlational rather than experimental nature of this research, causal statements cannot be made about the found effects.

Nevertheless, there were numerous notable strengths of the present research. First, actual turnover data was collected as opposed to relying on measures of turnover intentions. Turnover intentions are one of the most proximal predictors of voluntary turnover and measuring turnover intentions is a convenient way to assess precursory decisions to leave one's organization when data-collection must happen quickly. However, not all turnover intentions come to fruition. While both turnover intentions and voluntary turnover are related to withdrawal from one's organization, there is an appreciable difference between withdrawal cognitions and the decision to remove one's self from their organization. Thus, the quality of the current study is greatly 
enhanced by the analysis of authentic decisions to stay or leave one's organization.

In order to collect such records, time-lag data collection across the course of one year was required which is additional feat in organizational research. The present study analyzed turnover data from organizational records within a field sample. The use of such data enhances the ecological validity of the reported effects. By examining the moderating influences of participation in developmental activities and perceptions of career opportunities within an existing organization, the present findings are more generalizable to the greater organizational context and the practical implications can be considered with greater confidence. Additionally, the collection of data from a multinational European organization adds further evidence for the cross-cultural generalizability of the proactive personality construct. A sizable amount of proactivity research has involved American and Chinese samples, with fewer samples coming from European regions. The present research extends the investigation and interpretation of the effects of proactive personality to a new cultural context. Furthermore, the present study provides, to my knowledge, the first theoretical excogitation and analysis of moderators of the relation between proactive personality and voluntary turnover. The results of this study set the stage for future research, replications, and theoretical expansion to provide a heightened understanding of factors leading to turnover of highly valuable proactive employees.

\section{Implications for Research and Practice}

To provide further evidence for the theoretical foundation of the proposed relationships, future studies could directly assess employees' perceptions of their job embeddedness at an intermediate time point using measures like the 7-item survey utilized by Crossely, Bennet, Jex, and Burnfield (2007). Similarly, to make more certain claims regarding the theoretical basis in career motivation, measurement of the career resilience, insight, and identify components of 
career motivation (see Day \& Allen, 2004; London, 1993; Noe et al., 1990) could provide a refined understanding of the specific drivers of proactive-employee turnover. The current study examined participation in developmental activities and perceived career opportunities as moderators rather than mediators of the relation between proactive personality and voluntary due to the lack of casual data. Future studies could test these variables as mediators rather than moderators of the same relation if measures of participation in developmental activities and PCO are collected at an intermediate time point after measures of proactive personality, but before voluntary turnover. A challenging yet vastly informative opportunity would be to follow proactive individuals throughout their careers, collecting quantitative and qualitative information during exit interviews to gain insight into other moderators that might influence turnover decisions. Data could also be collected when these individuals begin working with organizations to qualitatively understand factors leading proactive employees to seek and pursue employment opportunities with certain companies. Such analyses could lend insight into other possible moderators that influence proactive individuals' staying behaviors, inspiring future research areas within the proactive personality domain.

Aside from collecting longitudinal data, there are still numerous opportunities to explore possible moderators and mechanisms explaining the proactive personality-turnover relationship. For instance, when considering that proactive individuals are active agents of their environments who take steps to bring about change (Bateman \& Crant, 1993), certain job characteristics, or lack thereof, may thwart their proactive efforts and influence their turnover decisions. This is most apparent with the autonomy dimension of Hackman and Oldham's (1976) Job Characteristics Model (JCM), a classic model linking job dimensions and psychological states to important organizational outcomes such as motivation, performance, satisfaction, and 
withdrawal. If proactive individuals hold roles where they are tightly constrained and unable to exert their influence on the surrounding environment, they may be more likely to turnover in search of roles with more autonomy. Relatedly, one psychological state at the causal core of the JCM is felt responsibility for work outcomes. If an employee's proactive influence in the workplace leads to a valued sense of experienced responsibility for work outcomes, they may be more likely to stay within their current roles. Therefore, future research could examine whether autonomy or perceived responsibility for results moderate the proactive-turnover relationship. Additionally, to address the finding that the relation between proactive personality and voluntary turnover was constant when participation in developmental activities was low, future studies may want to investigate moderators such as self-efficacy or the state of the job market to see if considerations about perceived control may have constrained this relationship.

Even if proactive individuals have turnover intentions, decisions to act upon them may be highly dependent upon other considerations such as perceptions of employability, perceived alternatives, and tenure/seniority or career stage. In future research, each of these could also be examined as moderators of the proactive personality-turnover relation. As previously mentioned within the limitations of this study, future research should tease apart organizationally-sanctioned developmental activities from self-directed developmental activities. This would clarify whether the effects of participation in developmental activities are due to perceived organizational support for development. Similarly, future research could explore whether supervisory support for development influences participation. If proactive individuals do not feel that they have supervisory support backing them in their pursuits, they may seek such support elsewhere. 
The results of the current research have meaningful implications for organizations. Increased participation in developmental activities was associated with a decrease in the probability of turnover. Thus, to bolster retention effects, organizations should encourage employees to participate in career enhancing activities such as taking continuing education courses, attending workshops and training, or taking on new job assignments. An interaction showed that this effect was more drastic for employees scoring lower on proactivity, suggesting retention efforts such as these would be more effective for non-proactive employees.

Meta-analytic research has already established proactive personality as a significant predictor of job performance, and employing proactive individuals clearly adds value to any work team. However, identifying and selecting proactive employees is just the first step. To reap the benefits of a proactive workforce, organizations must know how to build the circumstances that draw proactive individuals in and prevent those that push them out of organizations. The results of the current study provide evidence that can be used to create the right retention conditions. Highly proactive employees were more likely to stay in their organization when they perceived career opportunities, but more likely to turnover when they did not perceive available career opportunities. While PCO is a subjective construct by nature, organizations can still take steps to make opportunities more salient to proactive employees. For example, managers could have discussions with employees about their ideal career trajectories and how those goals might align with available positions in the organization. By outlining potential paths for advancement, facilitating discussions about available opportunities, and making opportunities salient in the workplace, proactive employees are likely to perceive more career opportunities, which, as evidenced by the results of the current study, is associated with a decreased likelihood of voluntary turnover. 
In conclusion, the present study has laid the groundwork for uncovering the nature of the relationship between proactive personality and voluntary turnover, as well as for identifying boundary conditions of this relation. Consistent with job embeddedness theory and career motivation theory, participation in developmental activities and perceived career opportunities interacted with proactive personality to explain the probability of voluntary turnover. As employees participate in more career enhancing activities, their likelihood of turnover decreases. Additionally, proactive employees are likely to remain with their organizations when career options are perceived to be available, but are more likely to turnover when opportunities are not perceived to be available. Practically, this suggests participation in developmental activities should be encouraged in the workplace and that potential career opportunities should be made salient to individuals with proactive personalities in order to retain these highly productive employees. 


\section{REFERENCES}

Allen, N. J., \& Meyer, J. P. (1990). The measurement and antecedents of affective, continuance and normative commitment to the organization. Journal of Occupational Psychology, 63(1), 1-18. doi:10.1111/j.2044-8325.1990.tb00506.x

Allen, D. G., Shore, L., \& Griffeth, R. (2003). The role of perceived organizational support and supportive human resource practices in the turnover process. Journal of Management, 29(1), 99-118. http://doi.org/10.1177/014920630302900107

Allen, D. G., Weeks, K. P., \& Moffitt, K. R. (2005). Turnover intentions and voluntary turnover: The moderating roles of self-monitoring, locus of control, proactive personality, and risk aversion. Journal of Applied Psychology, 90(5), 980-990. http://doi.org/10.1037/00219010.90 .5 .980

Arthur, M. B. (1994). The boundaryless career: A new perspective for organizational inquiry. Journal of Organizational Behavior, 15(4), 295-306. http://doi.org/10.1002/job.4030150402

Arthur, M. B. (1998). The boundaryless career: A new employment principle for a new organizational era. Academy of Management Review, 23(1), 176-178. http://doi.org/10.5465/AMR.1998.192975

Bakker, A. B., Schaufeli, W. B., Leiter, M. P., \& Taris, T. W. (2008). Work engagement: An emerging concept in occupational health psychology. Work \& Stress, 22(3), 187-200. http://doi.org/10.1080/02678370802393649

Bakker, A. B., Tims, M., \& Derks, D. (2012). Proactive personality and job performance: The role of job crafting and work engagement. Human Relations, 65(10), 1359-1378. http://doi.org/10.1177/0018726712453471 
Bambacas, M., \& Kulik, C. T. (2012). Job embeddedness in China: How HR practices impact turnover intentions. The International Journal of Human Resource Management, 24(10), 120. http://doi.org/10.1080/09585192.2012.725074

Bandura, A. (1977). Self-efficacy: Toward a unifying theory of behavioral change. Psychological Review, 84(2), 191-215. http://doi.org/10.1037/0033-295X.84.2.191

Bandura, A. (1986). Social foundations of thought and action: A social cognitive theory. Englewood Cliffs, NJ: Prentice-Hall, Inc.

Bandura, A. (1989). Social cognitive theory: An agentic perspective. Annual Review of Psychology, 52(6), 1-60. http://doi.org/10.1146/annurev.psych.52.1.1

Bandura, A. (1999). Social cognitive theory of personality. In Handbook of Personality: Theory and Research (pp. 154-196). Guilford Publications Guilford Press. http://doi.org/10.1016/0749-5978(91)90022-L

Barnett, B. R., \& Bradley, L. (2007). The impact of organisational support for career development on career satisfaction. Career Development International, 12(17), 617-636. http://dx.doi.org/10.1108/13620430710834396

Barrick, M. R., \& Mount, M. K. (1996). Effects of impression management and self-deception on the predictive validity of personality constructs. Journal of Applied Psychology, 81(3), 261-272. http://doi.org/10.1037/0021-9010.81.3.261

Bateman, T. S., \& Crant, J. M. (1993). The proactive component of organizational behavior: A measure and correlates. Journal of Organizational Behavior, 14(2), 103-118. http://doi.org/10.1002/job.4030140202

Bateman, T. S., \& Crant, J. M. (1999). Proactive behavior: Meaning, impact, recommendations. Business Horizons, 42(3), 63-70. http://doi.org/10.1016/S0007-6813(99)80023-8 
Bedeian, A. G., Kemery, E. R., \& Pizzolatto, A. B. (1991). Career commitment and expected utility of present job as predictors of turnover intentions and turnover behavior. Journal of Vocational Behavior, 39(3), 331-343. http://doi.org/10.1016/0001-8791(91)90042-K

Benson, G. S., Finegold, D., \& Mohrman, S. A. (2004). You paid for the skills, now keep them: Tuition reimbursement and voluntary turnover. Academy of Management Journal, 47(3), 315-331. http://doi.org/10.2307/20159584

Bergeron, D. M., Schroeder, T. D., \& Martinez, H. A. (2014). Proactive personality at work: Seeing more to do and doing more? Journal of Business and Psychology, 29(1), 71-86. http://doi.org/10.1007/s10869-013-9298-5

Bertolino, M., \& Fraccaroli, F. (2011). Age as moderator of the relationship of proactive personality with training motivation, perceived career development from training, and training behavioral intentions. Journal of Organizational Behavior, 32, 248-263. http://doi.org/doi.org/10.1002/job.670

Bindl, U. K., \& Parker, S. K. (2011). Proactive work behavior: Forward-thinking changeoriented action in organizations. APA Handbook of Industrial and Organizational Psychology, 2, 567-598. http://doi.org/doi:10.1037/12170-000

Blau, P. M. (1964). Exchange and power in social life. New York: JohnWiley.

Bowers, K. S. (1973). Situationism in psychology: An analysis and a critique. Psychological Review, 80(5), 307-336. http://doi.org/10.1037/h0021465

Briscoe, J. P., Hall, D. T., \& Frautschy DeMuth, R. L. (2006). Protean and boundaryless careers: An empirical exploration. Journal of Vocational Behavior, 69, 30-47. http://doi.org/10.1016/j.jvb.2005.09.003

Cai, Z., Guan, Y., Li, H., Shi, W., Guo, K., Liu, Y., ... Hua, H. (2015). Self-esteem and 
proactive personality as predictors of future work self and career adaptability: An examination of mediating and moderating processes. Journal of Vocational Behavior, 86, 86-94. http://doi.org/10.1016/j.jvb.2014.10.004

Campbell, D. J. (2000). The proactive employee: Managing workplace initiative. Academy of Management Perspectives, 14(3), 52-66. http://doi.org/10.5465/AME.2000.4468066

Chan, D. (2006). Interactive effects of situational judgment effectiveness and proactive personality on work perceptions and work outcomes. Journal of Applied Psychology, 91(2), 475-481. http://doi.org/10.1037/0021-9010.91.2.475

Chay, Y., \& Aryee, S. (1999). Potential moderating influence of career growth opportunities on careerist orientation and work attitudes: Evidence of the protean career era in Singapore. Journal of Organizational Behavior, 20(5), 613-623. http://doi.org/10.1002/(SICI)10991379(199909)20:5<613::AID-JOB979>3.0.CO;2-A

Chung-Yan, G. A., \& Butler, A. M. (2011). Proactive personality in the context of job complexity. Canadian Journal of Behavioural Science, 43(4), 279-286. http://doi.org/10.1037/a0024501

Cohen, J., Cohen, P., West, L. S., \& Aiken, S. G. (2002). Applied multiple regression/correlation analysis for the behavioral sciences. Mahwah, NJ: Erlbaum.

Colquitt, J. A., LePine, J. A., \& Noe, R. A. (2000). Toward an integrative theory of training motivation: A meta-analytic path analysis of 20 years of research. Journal of Applied Psychology, 85(5), 678-707. http://doi.org/10.1037//0021-9010.g5.5.678

Converse, P. D., Pathak, J., DePaul-Haddock, A. M., Gotlib, T., \& Merbedone, M. (2012). Controlling your environment and yourself: Implications for career success. Journal of Vocational Behavior, 80(1), 148-159. http://doi.org/10.1016/j.jvb.2011.07.003 
Crant, J. M. (1995). The proactive personality scale and objective job performance among real estate agents. Journal of Applied Psychology, 80(4), 532-537. http://doi.org/10.1037/00219010.80 .4 .532

Crant, J. M. (2000). Proactive behavior in organizations. Journal of Management, 26(3), 435462. http://doi.org/10.1177/014920630002600304

Crant, J. M., Hu, J., \& Jiang, K. (n.d.). Proactive Personality: A Twenty-year Review.

Crossley, C., Bennet, R. J., Jex, S. M., \& Burnfield, J. L. (2007). Development of a global measure of job embeddedness and integration into a traditional model of voluntary turnover. Journal of Applied Psychology, 92(4), 1031-1042. http://doi.org/10.1037/a0025569

Cropanzano, R., \& Mitchell, M. S. (2005). Social exchange theory: An interdisciplinary review. Journal of Management, 31(6), 874-900. http://doi.org/10.1177/0149206305279602

Day, R., \& Allen, T. D. (2004). The relationship between career motivation and self-efficacy with protégé career success. Journal of Vocational Behavior, 64(1), 72-91. http://doi.org/10.1016/S0001-8791(03)00036-8

Diefendorff, J. M., Hall, R. J., Lord, R. G., \& Strean, M. L. (2000). Action-state orientation: Construct validity of a revised measure and its relationship to work-related variables. Journal of Applied Psychology. 85(2), 250-263. http://doi.org/10.1037//0021-9010.85.2.250

Eisenberger, R., Armeli, S., Rexwinkel, B., Lynch, P. D., \& Rhoades, L. (2001). Reciprocation of perceived organizational support. Journal of Applied Psychology, 86(1), 42-51. http://doi.org/10.1037//0021-9010.86.1.42

Erdogan, B., \& Bauer, T. N. (2005). Enhancing career benefits of employee proactive personality: The role of fit with jobs and organizations. Personnel Psychology, 58(4), 859891. http://doi.org/10.1111/j.1744-6570.2005.00772.x 
Fredrickson, B. L. (2001). The role of positive emotions in positive psychology. American Psychologist, 56(3), 218-226. http://doi.org/10.1O37//0OO3-O66X.56.3.218

Fuller, B., \& Marler, L. E. (2009). Change driven by nature: A meta-analytic review of the proactive personality literature. Journal of Vocational Behavior, 75(3), 329-345. http://doi.org/10.1016/j.jvb.2009.05.008

Fuller Jr., J. B., Kester, K., \& Cox, S. S. (2010). Proactive personality and job performance: Exploring job autonomy as a moderator. Journal of Managerial Issues, 22(1), 35-51. http://doi.org/10.2307/25822514

Garofano, C. M., \& Salas, E. (2005). What influences continuous employee development decisions? Human Resource Management Review, 15(4), 281-304. http://doi.org/10.1016/j.hrmr.2005.10.002

Gouldner, A. W. (1960). The norm of reciprocity: A preliminary statement. American Sociological Review, 25(2), 161-178. http://doi.org/10.2307/2092623

Greer, J. A. (2014). Utility analysis: Implementation before integration. Industrial and Organizational Psychology, 7(4), 569-570. http://doi.org/doi:10.1111/iops.12196

Greguras, G. J., \& Diefendorff, J. M. (2010). Why does proactive personality predict employee life satisfaction and work behaviors? A field investigation of the mediating role of the selfconcordance model. Personnel Psychology, 63(3), 539-560. http://doi.org/doi:10.1111/j.1744-6570.2010.01180.x

Hackman, J. R., \& Oldham, G. R. (1976). Motivation through the design of work: Test of a theory. Organizational behavior and human performance, 16(2), 250-279.

Hall, D. T. (1987). Careers and Socialization. Journal of Management, 13(2), 301-321. http://doi.org/doi:10.1177/014920638701300207 
Hall, D. T. (2004). The protean career: A quarter-century journey. Journal of Vocational Behavior, 65, 1-13. http://doi.org/10.1016/j.jvb.2003.10.006

Hayes, A. F., \& Matthes, J. (2009). Computational procedures for probing interactions in OLS and logistic regression: SPSS and SAS implementations. Behavior research methods, 41(3), 924-936.

Heavey, A. L., Holwerda, J. A., \& Hausknecht, J. P. (2013). Causes and consequences of collective turnover: A meta-analytic review. Journal of Applied Psychology, 98(3), 412453. http://doi.org/10.1037/a0032380

Holtom, B. C., Mitchell, T. R., \& Lee, T. W. (2006). Increasing human and social capital by applying job embeddedness theory. Organizational Dynamics, 35(4), 316-331. http://doi.org/10.1016/j.orgdyn.2006.08.007

Holtom, B. C., Mitchell, T. R., Lee, T. W., \& Eberly, M. B. (2008). Turnover and retention research: A glance at the past, a closer review of the present, and a venture into the future. Academy of Management Annals, 2(1), 231-274.

http://doi.org/10.1080/19416520802211552

Hurtz, G. M., \& Williams, K. J. (2009). Attitudinal and motivational antecedents of participation in voluntary employee development activities. Journal of Applied Psychology, 94(3), 635. http://doi.org/10.1037/a0014580

Ito, J. K., \& Brotheridge, C. M. (2005). Does supporting employees' career adaptability lead to commitment turnover, or both? Human Resource Management, 44(1), 5-19. http://doi.org/10.1002/hrm.20037

Joo, B.-K., Hahn, H.-J., \& Peterson, S. L. (2015). Turnover intention: The effects of core selfevaluations, proactive personality, perceived organizational support, developmental 
feedback, and job complexity. Human Resource Development International, 18(2), 116130. http://doi.org/10.1080/13678868.2015.1026549

Kraimer, M. L., Seibert, S. E., Wayne, S. J., Liden, R. C., \& Bravo, J. (2011). Antecedents and outcomes of organizational support for development: The critical role of career opportunities. Journal of Applied Psychology, 96(3), 485-500. http://doi.org/10.1037/a0021452

Li, L., Zhong, J. an, Chen, Y., Xie, Y., \& Mao, S. (2014). Moderating effects of proactive personality on factors influencing work engagement based on the job demands-resources model. Social Behavior \& Personality: An International Journal, 42(1), 7-16. http://doi.org/10.2224/sbp.2014.42.1.7

Li, M., Liu, Y., Liu, L., \& Wang, Z. (2016). Proactive Personality and innovative work behavior: The mediating effects of affective states and creative self-efficacy in teachers. Current Psychology, 1-10. http://doi.org/10.1007/s12144-016-9457-8

Li, M., Wang, Z., Gao, J., \& You, X. (2017). Proactive Personality and job satisfaction: The mediating effects of self-efficacy and work engagement in teachers. Current Psychology, 36(1), 48-55. http://doi.org/10.1007/s12144-015-9383-1

Li, N., Barrick, M. R., Zimmerman, R. D., \& Chiaburu, D. S. (2014). Retaining the productive employee: The role of personality. The Academy of Management Annals, 8(1), 348-395. http://doi.org/10.1080/19416520.2014.890368

London, M. (1983). Toward a theory of career motivation. Academy of Management Review, 8(4), 620-630. http://doi.org/10.1007/s10551-009-0348-x

London, M. (1993). Relationships between career motivation, empowerment and support for career development. Journal of Occupational and Organizational Psychology, 66(1), 55- 
69. http://doi.org/10.1111/j.2044-8325.1993.tb00516.x

London, M., \& Noe, R. A. (1997). London's career motivation theory: An update on measurement and research. Journal of Career Assessment, 5(1), 61-80. http://doi.org/10.1177/106907279700500105

Major, D. A., Turner, J. E., \& Fletcher, T. D. (2006). Linking proactive personality and the big five to motivation to learn and development activity. Journal of Applied Psychology, 91(4), 927-935. http://doi.org/10.1037/0021-9010.91.4.927

Maurer, T. J., \& Chapman, E. F. (2013). Ten years of career success in relation to individual and situational variables from the employee development literature. Journal of Vocational Behavior, 83(3), 450-465. http://doi.org/10.1016/j.jvb.2013.07.002

Mischel, W. (1977). The interaction of person and situation. In D. Magnusson and N.S. Endler (Eds.), Personality at the crossroads: Current issues in interactional psychology (333-352). Hillsdale, NJ: Erlbaum.

Mischel, W., \& Shoda, Y. (2010). The situated person. In Mesquita, B., Barrett, L. F., \& Smith, E. R. (Eds.). The Mind in Context (149-173). Guilford Press.

Mitchell, T. R., Holtom, B. C., Lee, T. W., Sablynski, C. J., \& Erez, M. (2001). Why people stay: Using job embeddedness to predict voluntary turnover. Academy of Management Journal, 44(6), 1102-1121. http://doi.org/10.2307/3069391

Noe, R. A., Noe, A. W., \& Bachhuber, J. A. (1990). An investigation of the correlates of career motivation. Journal of Vocational Behavior, 37(3), 340-356. http://doi.org/10.1016/00018791(90)90049-8

Ok, A. B., \& Vandenberghe, C. (2016). Organizational and career-oriented commitment and employee development behaviors. Journal of Managerial Psychology, 31(5), 930-945. 
http://doi.org/http://dx.doi.org/10.1108/JMP-04-2015-0157

Orvis, K. A., \& Leffler, G. P. (2011). Individual and contextual factors: An interactionist approach to understanding employee self-development. Personality and Individual Differences, 51(2), 172-177. http://doi.org/10.1016/j.paid.2011.03.038

Parasuraman, S. (2010). Predicting turnover intentions and turnover behaviour: A multivariate analysis. Journal of Vocational Behavior, 21, 111-121. http://doi.org/10.1016/00018791(82)90056-2

Ployhart, R., \& Moliterno, T. (2011). Emergence of the human capital resource: A multilevel model. Academy of Management Review, 36(1), 127-150. http://doi.org/10.5465/AMR.2011.55662569

Podsakoff, N. P., LePine, J. A., \& LePine, M. A. (2007). Differential challenge stressorhindrance stressor relationships with job attitudes, turnover intentions, turnover, and withdrawal behavior: A meta-analysis. Journal of Applied Psychology, 92(2), 438-54. http://doi.org/10.1037/0021-9010.92.2.438

Porath, C., Spreitzer, G., Gibson, C., \& Garnett, F. G. (2012). Thriving at work: Toward its measurement,, construct validation, and theoretical refinement. Journal of Organizational Behavior, 33, 250-275. http://doi.org/10.1002/job

Presbitero, A. (2015). Proactivity in career development of employees: The roles of proactive personality and cognitive complexity. Career Development International, 20(5), 525-538. http://doi.org/10.1108/CDI-03-2015-0043

Rahman, W., \& Nas, Z. (2013). Employee development and turnover intention: Theory validation. European Journal of Training \& Development, 37(6), 564-579. http://doi.org/10.1108/EJTD-May-2012-0015 
Schneider B. (1983). Interactional psychology and organizational behavior. In Cummings L. L., Staw B. M. (Eds.). Research in Organizational Behavior, Vol 5 (pp. 1-31). Greenwich, CT: JAI Press.

Seibert, S. E., Crant, J. M., \& Kraimer, M. L. (1999). Proactive Personality and Career Success. Journal of Applied Psychology, 84(3), 416-427. http://doi.org/doi.org/10.1037/00219010.84 .3 .416

Seibert, S. E., Kraimer, M. L., \& Crant, J. M. (2001). What do proactive people do? A longitudinal model linking proactive personality and career success. Personnel Psychology, 54(4), 845-874. http://doi.org/doi.org/10.1111/j.1744-6570.2001.tb00234.x

Spitzmuller, M., Sin, H.-P., Howe, M., \& Fatimah, S. (2015). Investigating the uniqueness and usefulness of proactive personality in organizational research: A meta-analytic review. Human Performance, 28(4), 351-379. http://doi.org/10.1080/08959285.2015.1021041

Steel, R. P., \& Ovalle, N. K. (1984). A review and meta-analysis of research on the relationship between behavioral intentions and employee turnover. Journal of Applied Psychology, 69(4), 673-686. http://doi.org/10.1037/0021-9010.69.4.673

Sullivan, S. E., \& Arthur, M. B. (2006). The evolution of the boundaryless career concept: Examining physical and psychological mobility. Journal of Vocational Behavior, 69(1), 1929. http://doi.org/10.1016/j.jvb.2005.09.001

Thomas, J. P., Whitman, D. S., \& Viswesvaran, C. (2010). Employee proactivity in organizations: A comparative meta-analysis of emergent proactive constructs. Journal of Occupational \& Organizational Psychology, 83(2), 275-300.

http://doi.org/10.1348/09637910x502359

Thompson, J. A. (2005). Proactive personality and job performance: A social capital perspective. 
Journal of Applied Psychology, 90(5), 1011-1017. http://doi.org/10.1037/00219010.90 .5 .1011

Tolentino, L. R., Garcia, P. R. J. M., Lu, V. N., Restubog, S. L. D., Bordia, P., \& Plewa, C. (2014). Career adaptation: The relation of adaptability to goal orientation, proactive personality, and career optimism. Journal of Vocational Behavior, 84(1), 39-48. http://doi.org/10.1016/j.jvb.2013.11.004

Tornau, K., \& Frese, M. (2013). Construct clean-up in proactivity research: A meta-analysis on the nomological net of work-related proactivity concepts and their incremental validities. Applied Psychology: An International Review, 62(1), 44-96. http://doi.org/10.1111/j.14640597.2012.00514.x

Trifiletti, E., Capozza, D., Pasin, A., \& Falvo, R. (2009). A validation of the proactive personality scale. Testing, Psychometrics, Methodology in Applied Pscyhology, 16(2), 7793.

Tziner, A., \& Birati, A. (1996). Assessing employee turnover costs: A revised approach. Human Resource Management Review, 6(2), 113-122. http://doi.org/10.1016/S10534822(96)90015-7

Uy, M. A., Chan, K. Y., Sam, Y. L., Ho, M. H. R., \& Chernyshenko, O. S. (2015). Proactivity, adaptability and boundaryless career attitudes: The mediating role of entrepreneurial alertness. Journal of Vocational Behavior, 86, 115-123. http://doi.org/10.1016/j.jvb.2014.11.005

Vandenberghe, C., \& Ok, A. B. (2011). Career commitment, proactive personality, and work outcomes: a cross-lagged study. Career Development International, 18(7), 652-672. http://doi.org/10.1108/CDI-02-2013-0013 
Vandewalle, D. (1997). Development and validation of a work domain goal orientation instrument. Educational and Psychological Measurement, 57(6), 995-1015. http://doi.org/doi.org/10.1177/0013164497057006009

Wang, M., Zhan, Y., McCune, E., \& Truxillo, D. (2011). Understanding newcomers’ adaptability and work-related outcomes: Testing the mediating roles of perceived P-E fit variables. Personnel Psychology, 64(1), 163-189. http://doi.org/10.1111/j.1744$6570.2010 .01205 . x$

Wang, Y.-H., Hu, C., Hurst, C. S., \& Yang, C.-C. (2014). Antecedents and outcomes of career plateaus: The roles of mentoring others and proactive personality. Journal of Vocational Behavior, 85(3), 319-328. http://doi.org/10.1016/j.jvb.2014.08.003

Wayne, S. J., Shore, L. M., \& Liden, R. C. (1997). Perceived organizational support and leadermember exchange: A social exchange perspective. Academy of Management Journal, 40(1), 82-111. http://doi.org/10.2307/257021

Yang, J., Gong, Y., \& Huo, Y. (2011). Proactive personality, social capital, helping, and turnover intentions. Journal of Managerial Psychology, 26(8), 739-760. http://doi.org/10.1108/02683941111181806

Zimmerman, R. D. (2008). Understanding the impact of personality traits on individuals' turnover decisions: A meta-analytic path model. Personnel Psychology, 61(2), 309-348. http://doi.org/10.1111/j.1744-6570.2008.00115.x

Zimmerman, R., Swider, B., Woo, S., \& Allen, D. (2016). Who withdraws? Psychological individual differences and employee withdrawal behaviors. Journal of Applied Psychology, 101(4), 498-519. http://doi.org/10.1037/ap10000068 